This is the Author's Accepted Manuscript version of a paper published in WIRELESS PERSONAL COMMUNICATIONS by Springer International Publishing on 6 September 2014. The final publication is available at Springer via http://dx.doi.org/10.1007/s11277-014-2062-y.

\title{
LTE-Advanced Radio Access Enhancements: A Survey
}

\author{
Mohammad Dehghani \\ Electrical, Electronic and Computer Engineering \\ University of Greenwich, Chatham, Kent, United Kingdom \\ Email: arash.dehghani@gmail.com \\ Kamran Arshad \\ Electrical, Electronic and Computer Engineering \\ University of Greenwich, Chatham, Kent, United Kingdom \\ Email: k.arshad@gre.ac.uk \\ Richard MacKenzie \\ BT TSO \\ Adastral Park, Ipswich, England \\ Email: richard.mackenzie@bt.com
}

\begin{abstract}
Long Term Evolution Advanced (LTE-Advanced) is the next step in LTE evolution and allows operators to improve network performance and service capabilities through smooth deployment of new techniques and technologies. LTE-Advanced uses some new features on top of the existing LTE standards to provide better user experience and higher throughputs. Some of the most significant features introduced in LTE-Advanced are carrier aggregation, enhancements in heterogeneous networks, coordinated multipoint transmission and reception, enhanced Multiple Input Multiple Output (MIMO) usage and deployment of relay nodes in the radio network. Mentioned features are mainly aimed to enhance the radio access part of the cellular networks. This survey article presents an overview of the key radio access features and functionalities of the LTE-Advanced radio access network, supported by the simulation results. We also provide a detailed review of the literature together with a very rich list of the references for each of the features. An LTE-Advanced roadmap and the latest updates and trends in LTE markets are also presented.
\end{abstract}

Keywords LTE-Advanced, Carrier Aggregation, MIMO, Heterogeneous Network, Relay Nodes, CoMP Transmission and Reception

\section{Introduction}

Wireless mobile data traffic has increased tremendously in the last few years and is expected to increase 13-fold between 2012 and 2017 [1]. The leading driver for this increased growth of wireless data traffic, especially in cellular communications, is smartphones as shown in Fig. 1 [1] and Fig. 2 [2]. This increasing demand is pushing the existing wireless mobile networks towards their limits, causing a reduction in data throughput, decreasing the availability of resources and increasing data transmission delay. 


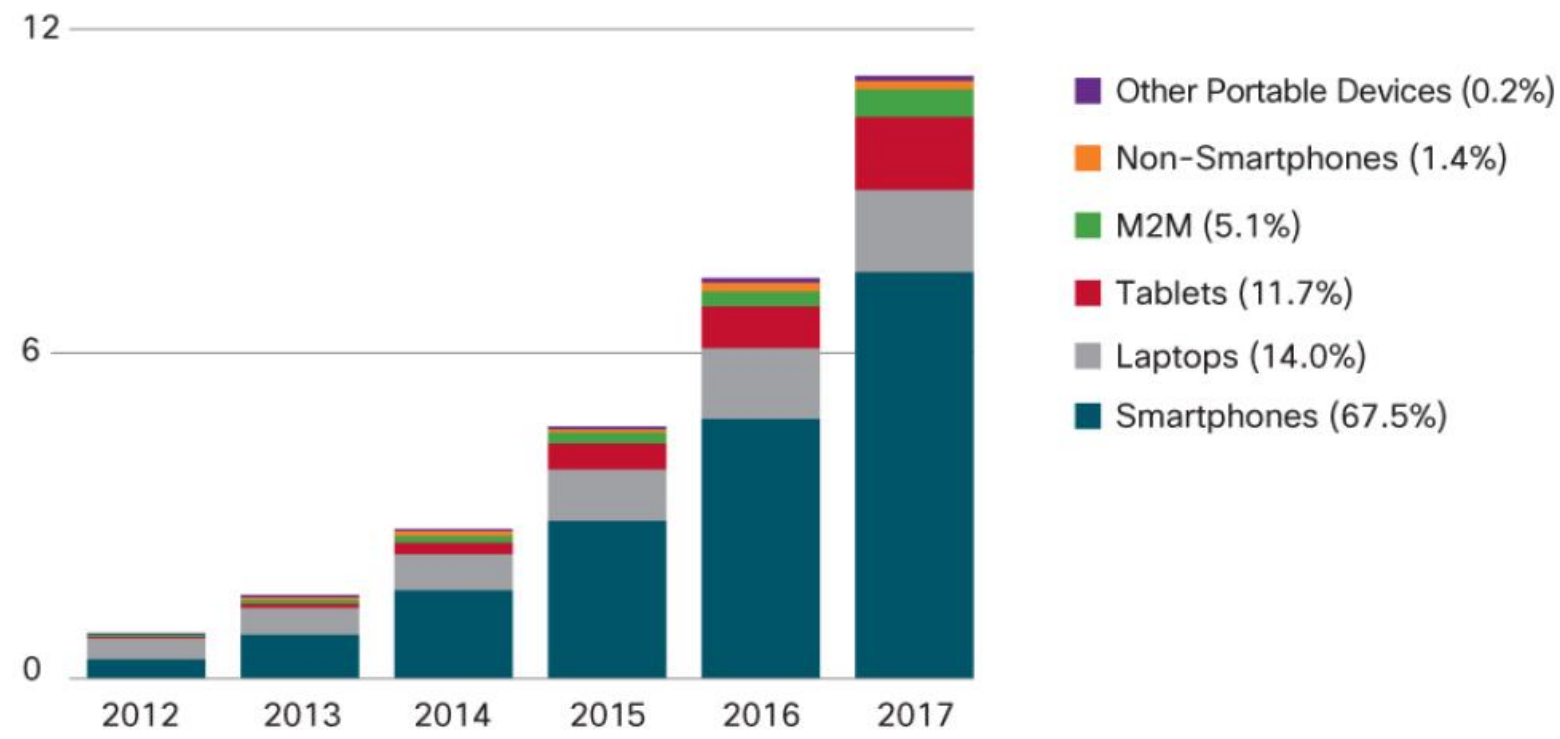

Fig. 1 Mobile data traffic growth [1]

Long Term Evolution of $3 \mathrm{G}$ (LTE) is one of the strongest candidates proposed by the $3^{\text {rd }}$ Generation Partnership Project (3GPP) for deploying globally as the next generation of wireless mobile networks (i.e. 4G). LTE has been the fastest developing mobile system to date and as of July 2014, 318 operators have commercially launched LTE systems worldwide [3]. The LTE expansions forecast illustrated in Fig. 3 [2] indicates that the LTE deployment trend will continue to increase in the coming years.

LTE standardisation was started in 3GPP release 8 with basic features such as Multiple Input Multiple Output (MIMO) support. The next release of LTE (i.e. release 9) did not introduce major changes in the radio capability of the LTE systems. Some complementary features, e.g. positioning and enhanced Multimedia Broadcast Messaging Service (MBMS) were enabled, but the offered data rates and capacity remained unchanged. In release 10 (also referred to as LTE-Advanced), significant modifications have been made in the radio capabilities and the peak and achievable data rates improved significantly. 


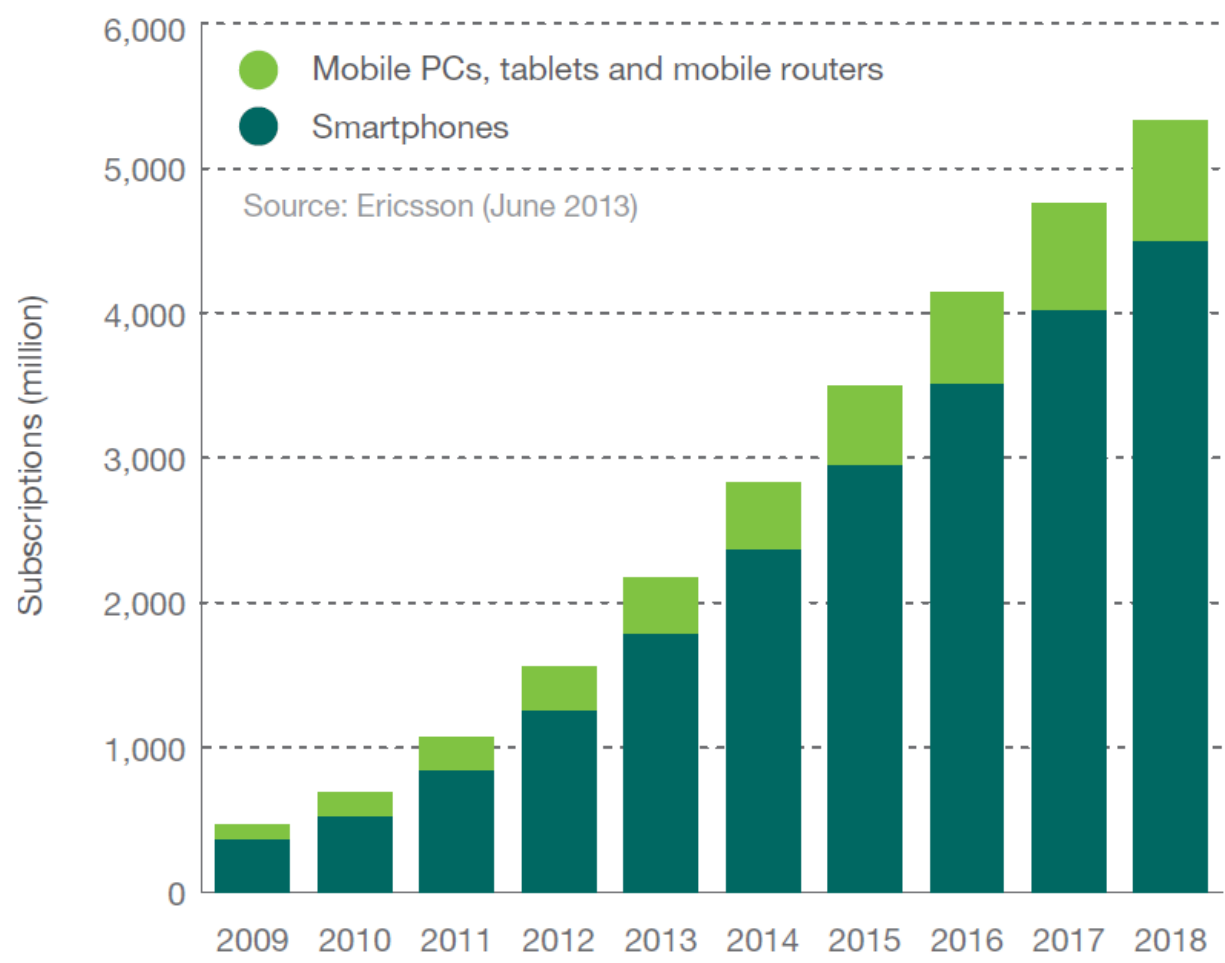

Fig. 2 Subscriptions with cellular connection [2]

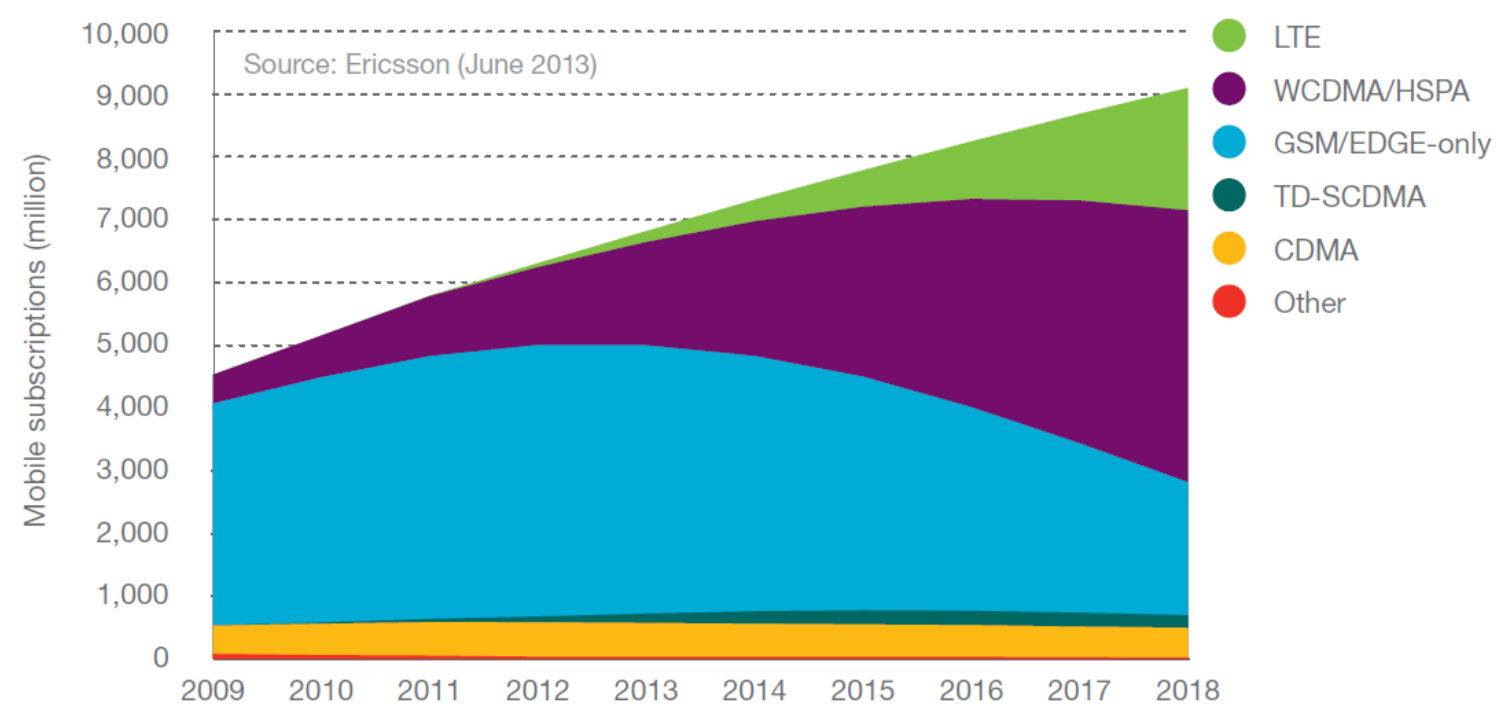

Fig. 3 Mobile subscriptions by technology [2]

LTE-Advanced is meant to fulfil the requirements of International Telecommunication Union - Radio communication sector (ITU-R) for International Mobile Telecommunication - Advanced (IMTAdvanced). The Key IMT-Advanced requirements are summarised as follows [4]:

- $100 \mathrm{Mbps}$ and $1 \mathrm{Gbps}$ peak data rates for high and low mobility cases respectively;

- Minimum $40 \mathrm{MHz}$ transmission bandwidth (and up to $100 \mathrm{MHz}$ is under consideration);

- Interworking with other radio access technologies and systems;

- Enabling high quality mobile services;

- Capability of worldwide roaming;

- Up to $350 \mathrm{~km} / \mathrm{h}$ mobility support;

- Voice Over IP(VoIP) capacity from 30 to 50 users/sector/MHz depending on the scenario; 
- Spectral efficiency from $0.7 \mathrm{bits} / \mathrm{Hz} / \mathrm{cell}$ to $3 \mathrm{bits} / \mathrm{Hz} / \mathrm{cell}$ depending on the scenario;

- Cell edge user spectral efficiency from $0.015 \mathrm{bps} / \mathrm{Hz}$ to $0.1 \mathrm{bps} / \mathrm{Hz}$ depending on the scenario;

Main features and techniques deployed in LTE-Advanced physical layer can be summarised as follows [5-13]:

- More transmission bandwidth using Carrier Aggregation (CA);

- Using more antennas and enhanced antenna techniques in the uplink and downlink transmission (MIMO enhancement);

- Cooperation between cells and Coordinated Multi Point (CoMP) transmission and reception;

- Using small cells and relays;

In this article, these LTE-Advanced key features are briefly explained, and a comprehensive list of references is provided to forward readers directly to more details regarding the current state of the art (SOTA). The improvements from LTE to LTE-Advanced are also illustrated and highlighted through link level simulation results. To the best of authors' knowledge, none of the existing articles (e.g. see [5-8]) provide such a comprehensive survey related to LTE-Advanced radio access features. In addition, the latest evolution trends and updates in LTE markets together with discussions regarding the current challenges and the future roadmap of LTE-Advanced are presented, which have rarely been discussed in the existing articles. Hence, it could have a significant contribution as a comprehensive survey article.

In section 2, the specifications of LTE and LTE-Advanced are overviewed, following with a specific section for each of the mentioned features of LTE i.e. Carrier aggregation (section 3), MIMO enhancement (section 4), Heterogeneous Network (section 5), Relaying (Section 6) and CoMP (section 7). Simulation results and discussions on the future road map of LTE-Advanced enhancements are presented in section 8 and section 9 respectively. Finally, the article is concluded in section 10 .

\section{LTE Systems Overview}

LTE was started as a study by 3GPP and first reported at a workshop in Canada in November 2004. The first complete set of standardisation was ready in March 2009. It was designed by 3GPP for years 2010 to 2020 and beyond and to compete with WiMAX technology introduced by IEEE. Some of the main drivers that push the different aspects of the LTE requirements are summarised in Table 1.

Table 1 LTE main drivers

\begin{tabular}{|c|c|}
\hline Driver & Aspect \\
\hline Wireline Evolution & Data Rate \\
\hline Extensive Wireless Data Usage & Capacity \\
\hline Flat Rate Pricing & Cost Efficiency \\
\hline Other Wireless Technologies & New Capabilities \\
\hline
\end{tabular}

Orthogonal Frequency Division Multiple Access (OFDMA) is used in LTE downlink with subcarrier spacing of $15 \mathrm{KHz}(7.5 \mathrm{KHz}$ subcarrier spacing is also supported for MBMS services). Resource assignment is done through assigning the sets of 12 consecutive subcarriers, called Resource Blocks (RB), to the users by scheduler. Considering the $15 \mathrm{KHz}$ spacing between subcarriers, the bandwidth of each RB is $180 \mathrm{KHz}(12 \times 15 \mathrm{KHz}=180 \mathrm{KHz})$. Number of RBs per cell is ranging from 6 to 100 corresponding to $1.4 \mathrm{MHz}$ to $20 \mathrm{MHz}$ bandwidth as shown in Table 2. Scalable bandwidth facilitates the deployment of LTE technology for mobile network operators. Small bandwidths can conveniently be used for refarming in lower frequencies such as $900 \mathrm{MHz}$, while higher bandwidths are basically suitable for refarming in higher frequencies to provide high data rates. 
Table 2 LTE bandwidths

\begin{tabular}{|c|c|c|c|c|}
\hline Bandwidth & $\begin{array}{c}\text { No. of Resource } \\
\text { Block }\end{array}$ & $\begin{array}{c}\text { No. of Data } \\
\text { Subcarrier }\end{array}$ & FFT Size & Sampling Rate \\
\hline $1.4 \mathrm{MHz}$ & 6 & 72 & 128 & $1.92 \mathrm{MHz}$ \\
\hline $3 \mathrm{MHz}$ & 15 & 180 & 256 & $3.84 \mathrm{MHz}$ \\
\hline $5 \mathrm{MHz}$ & 25 & 300 & 512 & $7.68 \mathrm{MHz}$ \\
\hline $10 \mathrm{MHz}$ & 50 & 600 & 1024 & $15.36 \mathrm{MHz}$ \\
\hline $15 \mathrm{MHz}$ & 75 & 900 & 1536 & $23.04 \mathrm{MHz}$ \\
\hline $20 \mathrm{MHz}$ & 100 & 1200 & 2048 & $30.72 \mathrm{MHz}$ \\
\hline
\end{tabular}

It can be seen from Table 2 that the sampling rates for all LTE bandwidths are set to be the multiplication of $3.84 \mathrm{MHz}$ in order to provide backward compatibility with WCDMA systems and facilitate the implementation of terminals that can support both LTE and WCDMA systems.

In the uplink, LTE uses Single Carrier-OFDMA (SC-OFDMA) technique. The main advantage of SCOFDMA over OFDMA is the 6 to $9 \mathrm{~dB}$ lower Peak to Average Power Ratio (PAPR) that results in less power consumption, less complex and less expensive Radio Frequency (RF) amplifiers in the user terminals. In addition, using only one carrier protects the system from interferences caused by frequency errors and the imperfect orthogonality between the subcarriers.

The main techniques that differentiate LTE radio access from other 3GPP technologies can be summarised as:

- OFDMA in downlink

- SC-FDMA in uplink

- Scalable bandwidth

- MIMO technology (HSPA systems also support MIMO technology in principle)

- Frequency domain scheduling

LTE release 8 and 9 meet the IMT-Advanced requirements in several areas such as high mobility support and latency. However, 3GPP set tight requirements for LTE-Advanced compared to IMTAdvanced in order to meet all the IMT-Advanced requirements confidently and also provide considerable improvements from release 8 and 9 to release 10 [14]. Table 3 compares LTE and LTEAdvanced fulfilments against IMT-Advanced and 3GPP requirements.

Table 3 Requirements and LTE fulfilments

\begin{tabular}{|c|c|c|c|c|}
\hline & $\begin{array}{l}\text { IMT-Advanced } \\
\text { Requirements }\end{array}$ & $\begin{array}{l}\text { 3GPP LTE-Advanced } \\
\text { Requirements }\end{array}$ & $\begin{array}{l}\text { LTE Release } 8 \\
\text { Achievements }\end{array}$ & $\begin{array}{l}\text { LTE-Advanced } \\
\text { Release } 10 \\
\text { Achievements }\end{array}$ \\
\hline $\begin{array}{l}\text { Downlink Peak } \\
\text { Spectrum } \\
\text { Efficiency } \\
\text { (bps/Hz) }\end{array}$ & $\begin{array}{l}15 \text { (max } 4 \\
\text { antennas) }\end{array}$ & 30 (max 8 antennas) & 16 & $\begin{array}{c}16(4 \times 4 \text { antenna } \\
\text { configuration) } \\
30(8 \times 8 \text { antenna } \\
\text { configuration })\end{array}$ \\
\hline $\begin{array}{l}\text { Uplink Peak } \\
\text { Spectrum } \\
\text { Efficiency } \\
\text { (bps/Hz) }\end{array}$ & $\begin{array}{c}6.75 \text { (max } 2 \mathrm{TX} \\
\text { antennas) }\end{array}$ & 15 (max 4 TX antennas) & 4 & $\begin{array}{c}8.1(2 \times 2 \text { antenna } \\
\text { configuration) } \\
16.1(4 \times 4 \text { antenna } \\
\text { configuration) }\end{array}$ \\
\hline $\begin{array}{l}\text { User Plane } \\
\text { Latency (ms) }\end{array}$ & 10 & 10 & 4.9 & 4.9 \\
\hline
\end{tabular}


Some of the main physical layer features in release 10 and subsequent releases of LTE-Advanced (i.e. release 11 and 12) are summarised in Table 4.

Table 4 LTE-Advanced features

\begin{tabular}{|c|c|c|}
\hline Release 10 & Release 11 & $\begin{array}{c}\text { Release 12 } \\
\text { (Study Items) }\end{array}$ \\
Carrier Aggregation & Carrier Aggregation enhancement & MIMO enhancement \\
Advanced MIMO & CoMP Transmission/Reception \\
Heterogeneous Network and \\
eICIC
\end{tabular}

At the time of writing this article, release 12 has not been finalised and documentation of specification started in September 2013 and will be completed by June 2014. Release 10 and 11 are already finalised.

Regarding the User Equipment (UE), LTE-advanced has defined three new classes in addition to the five classes in LTE release 8 and 9. Table 5 and 6 summarise LTE and LTE-advanced UE categories [15].

Table 5 LTE UE Category

\begin{tabular}{|c|c|c|c|c|c|}
\hline & Category 1 & Category 2 & Category 3 & Category 4 & Category 5 \\
\hline Peak Data Rate Downlink & $10 \mathrm{Mbps}$ & $50 \mathrm{Mbps}$ & $100 \mathrm{Mbps}$ & $150 \mathrm{Mbps}$ & $300 \mathrm{Mbps}$ \\
\hline Peak Data Rate Uplink & $5 \mathrm{Mbps}$ & $25 \mathrm{Mbps}$ & $50 \mathrm{Mbps}$ & $50 \mathrm{Mbps}$ & $75 \mathrm{Mbps}$ \\
\hline RF Bandwidth & $20 \mathrm{MHz}$ & $20 \mathrm{MHz}$ & $20 \mathrm{MHz}$ & $20 \mathrm{MHz}$ & $20 \mathrm{MHz}$ \\
\hline Modulation Downlink & $64 \mathrm{QAM}$ & $64 \mathrm{QAM}$ & $64 \mathrm{QAM}$ & $64 \mathrm{QAM}$ & $64 \mathrm{QAM}$ \\
\hline Modulation Uplink & $16 \mathrm{QAM}$ & $16 \mathrm{QAM}$ & $16 \mathrm{QAM}$ & $16 \mathrm{QAM}$ & $64 \mathrm{QAM}$ \\
\hline MIMO Downlink & Optional & $2 \times 2$ & $2 \times 2$ & $2 \times 2$ & $4 \times 4$ \\
\hline MIMO Uplink & No & No & No & No & No \\
\hline
\end{tabular}


Table 6 Categories added in LTE-Advanced

\begin{tabular}{|c|c|c|c|}
\hline & Category 6 & Category 7 & Category 8 \\
\hline Peak Data Rate Downlink & $300 \mathrm{Mbps}$ & $300 \mathrm{Mbps}$ & $3000 \mathrm{Mbps}$ \\
\hline Peak Data Rate Uplink & $50 \mathrm{Mbps}$ & $100 \mathrm{Mbps}$ & $1500 \mathrm{Mbps}$ \\
\hline RF Bandwidth & $40 \mathrm{MHz}$ & $40 \mathrm{MHz}$ & $100 \mathrm{MHz}$ \\
\hline Modulation Downlink & 64 QAM & 64 QAM & 64 QAM \\
\hline Modulation Uplink & 16 QAM & 16 QAM & 64 QAM \\
\hline MIMO Downlink & $\begin{array}{c}2 \times 2 \text { with CA } \\
4 \times 4 \text { without } C A\end{array}$ & $\begin{array}{c}2 \times 2 \text { with } C A \\
4 \times 4 \text { without } C A\end{array}$ & $8 \times 8$ \\
\hline MIMO Uplink & No & $2 \times 2$ & $4 \times 4$ \\
\hline
\end{tabular}

As of the date of writing this article, the majority of the LTE devices in the market are in category 3. A few mobile phones in category 4 have started to appear since the beginning of 2013. The first UE chipset that supports carrier aggregation was launched by Qualcomm in June 2013. It is used in category 4 UEs and supports two carriers with up to $10 \mathrm{MHz}$ of bandwidth each $(10 \mathrm{MHz}+10 \mathrm{MHz})$.

\section{Carrier Aggregation}

\subsection{Overview}

CA is considered to be the most important and effective feature of LTE-Advanced. The key idea in $\mathrm{CA}$ is to provide wider bandwidth for users by aggregating two or more release 8 LTE carriers as illustrated in Fig. 4 [16]. In LTE-Advanced, backward compatibility is achieved by aggregating several LTE carriers to increase transmission bandwidth without any significant changes to the LTE carriers. With CA, it is also possible to aggregate different carriers from different bands. Carrier aggregation is exciting for mobile network operators as large continuous bandwidths (i.e. on the order of $100 \mathrm{MHz}$ ) are scarce in several countries, including the United Kingdom. The network operators can aggregate several small bandwidths distributed among different frequency bands and provide larger bandwidths and the required QoS.

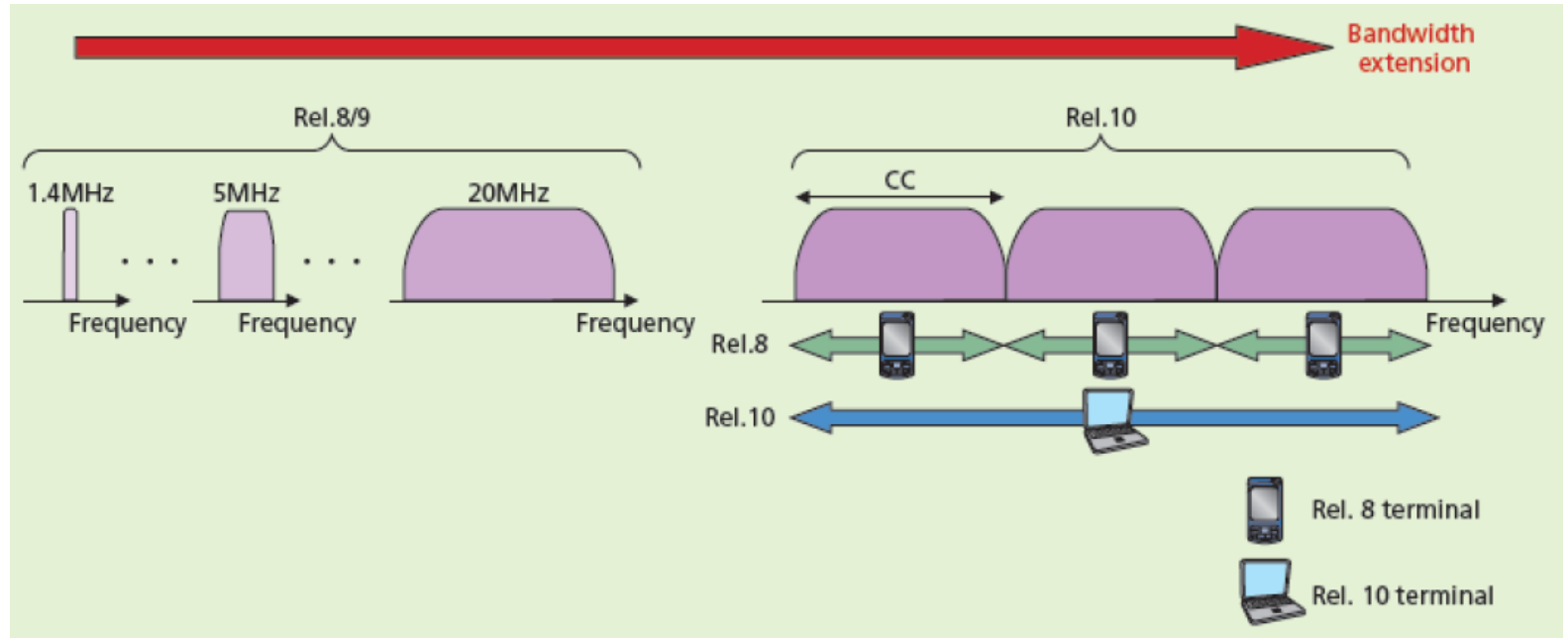

Fig. 4 Concept of LTE-Advanced CA [16] 
From the theoretical point of view, release 10 signalling supports aggregation of up to five carriers and have a bandwidth of $100 \mathrm{MHz}(5 \times 20 \mathrm{MHz})$. Due to the practical limitations of the devices, only the aggregation of two carriers is currently considered in release 10. CA can be applied on uplink and downlink independently, but the number of uplink Component Carriers (CCs) should not be more than the downlink CCs. This is due to the fact that each of the uplink CCs is scheduled via its corresponding downlink CC. The performance evaluation for the asymmetric bandwidth allocation between uplink and downlink was examined via experiments in $[17,18]$. In the mentioned experiments, two CCs $(40 \mathrm{MHz})$ in the uplink and five CCs $(100 \mathrm{MHz})$ in downlink were considered and based on the results, improvements in the Block Error Rate (BLER) of Uplink Control Information (UCI) were seen.

\subsection{Technical Aspects}

General aspects and performance analysis of CA are detailed in [19-27]. CA can improve the performance of the frequency domain scheduling. Several studies have been carried out regarding CC selection and scheduling in LTE-Advanced systems with CA [28-43]. In the case of CA, the scheduler can assign better resources by considering more than one carrier. In previous LTE releases that support only one carrier, the scheduler assigns the best resource block in the carrier by considering Channel State Information (CSI) and Channel Quality Indicator (CQI) feedback. By combining CA and frequency domain scheduling, the scheduler will receive the feedback from more than one carrier, therefore it is more likely to find a suitable RB for the transmission. In addition, when the aggregated carriers are from the different bands, more flexible and efficient management is possible. For instance, UEs that only support lower frequency bands can be moved to the lower frequency, and higher frequency bands can be assigned to the UEs capable to work in high frequency bands. Also, it would be possible to assign more suitable frequency bands to the cell edge users and provide them with higher data rates and better channel conditions [30,41,42]. Based on these aspects of this feature, it is concluded that $\mathrm{CA}$ is not only able to increase the data rate for the users close to the Base Station (BS), but also can improve cell edge user throughput as well. However, it should be noted that in principle, CA does not offer any spectral efficiency or overall throughput improvement for a fully loaded network. Hence, the average throughput gain achieved by CA feature is decreased by increasing the number of users [44].

From the protocol point of view, impact of CA is limited to Medium Access Control (MAC) layer and the physical layer and has no impact on the core network. Core network would not know what is going on in the radio side and it only senses that the data rate exceeds the usual values. Thus, CA is not visible to the layers above the MAC layer and data is divided between CCs in MAC layer. As illustrated in Fig. 5, each CC has its own physical layer, therefore non-CA capable UEs can be easily served by any of the $\mathrm{CC}$ independently. 


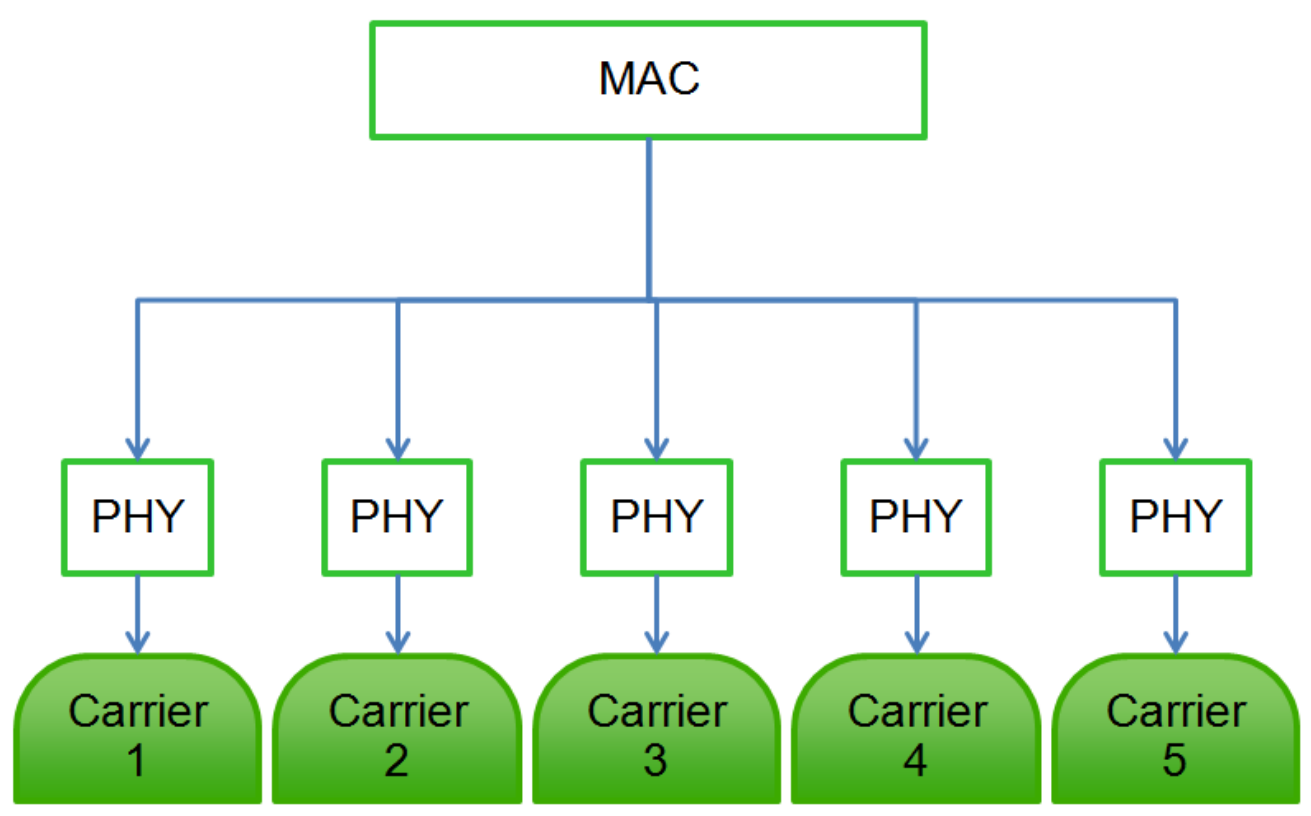

Fig. 5 CA structure

For UE attachment signalling procedure in the presence of the CA feature, the UE provides information about its CA capabilities, including information about its Primary CC (PCC) and any additional CC/CCs called Secondary CC (SCC). Once the Radio Resource Control (RRC) reconfiguration is completed, the MAC layer can activate and configure the SCC. In the case of lack of activities, a specific timer can be set to deactivate the SCC and prevent the UE from sending CSI and CQI measurement for the deactivated SCC. This reduces energy consumption in UEs and prolongs battery life.

\section{MIMO Enhancement}

\subsection{Overview}

MIMO is a key technology in wireless communications that has potential to increase the channel capacity by using multiple transmitter and receiver antennas. The term comes from the fact that the transmission antennas are handled as the input to the propagation channel (which is the air interface), whereas receiver antennas are the output of it. The very basic ideas behind MIMO were introduced in 1970 [45], but MIMO technology had not been deployed in wireless communications till 1990. This feature is currently used in IEEE $802.11 \mathrm{n}, 802.16 \mathrm{~d} / \mathrm{e}$ systems and supported by LTE release 8 . It has already been deployed widely in LTE networks and further enhancements were proposed in release 10. In LTE-Advanced, Single User MIMO (SU-MIMO) is extended to support eight transmit antennas while in release 8 , the maximum number of transmit antennas is four. In [46], performance evaluation of a single carrier LTE-Advanced system using 8 by $8 \mathrm{MIMO}$ and $20 \mathrm{MHz}$ of bandwidth shows that in an indoor scenario the median throughput of $335 \mathrm{Mbps}$ can be achieved. The eight transmit antennas at the base station can also be deployed in the transmission diversity scenarios [47]. General review of the multi antenna transmission techniques in 3GPP technologies from GSM to LTEAdvanced is presented in [48]. References [49-51] focus on MIMO techniques in LTE-Advanced system.

Furthermore, LTE-Advanced brings some enhancements of Multi User MIMO (MU-MIMO). MUMIMO can increase the network capacity, which is not achievable in SU-MIMO systems [52]. Many studies on different aspects of LTE-Advanced MU-MIMO such as performance evaluation [53-59], interference and channel estimation [60-62], feedback and signalling design and improvement [6366], scheduling [67-69], beamforming [70,71], techniques to improve the throughput [72], and its 
deployment alongside other LTE-Advanced features such as CA [73,74] and CoMP [75] have been done.

\subsection{Technical Aspects}

In LTE-Advanced release 10, new techniques such as improved feedback and pre-coding, interference cancellation at the receiver and more flexibility in frequency domain scheduling were introduced. In addition, new techniques in reference signals were also introduced in release 10 [76,77]. An adaptive design method for the reference signals in LTE-Advanced was also proposed in [78]. Typically, by increasing the number of antennas, the number of required reference symbols and system overhead increase while power efficiency decreases. As the number of MIMO antennas supported in LTEAdvanced increased to eight, 3GPP decided to come up with a new reference signal structure to minimise the overhead. In the new structure, the reference signal is divided into two different signals. The first one is called Channel State Information Reference Symbol (CSI-RS) and used for CQI, Precoding Matrix Indicator (PMI) and Rank Indicator (RI) measurement and reporting. The second one is Demodulation Reference Symbol (DM-RS) which is used for channel estimation and data demodulation. DM-RS is a user specific signal and it is proportional to the number of users. It means in release 10, unlike the previous generations and technologies, each user has a specific reference symbol that can also be used for other purposes such as beamforming. CSI-RS transmission occurs less frequently than DM-RS and deploying these two types of reference symbols instead of the legacy LTE reference symbol reduces the total overhead.

Feedback signalling was also modified in release 10 and a new codebook for 8 transmit antennas was added based on double codebook principle $[79,80]$. The feedback is divided into short-term and longterm feedback to reduce overall feedback transmission. Long-term feedback contains information about long term parameters, while the short term feedback is relevant to SU-MIMO operation.

Regarding the uplink, in release 8 it was only possible to have MU-MIMO, while release 10 supports SU-MIMO as well. In addition, MU-MIMO is enhanced due to the enhancement of the uplink reference signal in LTE-Advanced [81]. An overview of uplink MIMO in LTE-Advanced is presented in [82]. A combination between the collaborative system and the precoded MIMO using a space frequency block codes (SFBC) for the uplink is also proposed in [83].

LTE-Advanced uses closed loop precoder selection and the base station provides feedback to the terminal. Some experimental evaluation results of the uplink SU-MIMO with closed loop precoding can be found in $[84,85]$. The network can also obtain CSI based on the Sounding Reference Symbols (SRS) sent by UE.

The uplink multiple access scheme in LTE and LTE-Advanced, i.e. SC-OFDMA, is also regarded as Discrete Fourier Transform Spread OFDMA (DFT-S-OFDMA). LTE-Advanced supports clustered DFT-S-OFDM technique as the standard technology in the uplink which works closely with uplink MIMO [86-89]. In this technique, a maximum of 2 non-contiguous frequency clusters can be allocated to a UE. Multi-cluster transmission provides higher average cell throughput by offering more flexibility in frequency scheduling and higher frequency diversity gain [90].

While the typical detection algorithm for MIMO detection in LTE and LTE-Advanced systems is Order Successive Interference Cancellation (OSIC), an alternative Adaptive Hybrid Interference Cancellation (AHIC) in uplink is proposed in [91].

\section{Heterogeneous Network (HetNet)}

\subsection{Overview}

In general, a simple solution for capturing the high traffic increase trend and having more capacity and coverage is to have more base station in the network. One approach is to use small cells rather than adding more macro base stations. HetNet refers to a network that contains macro base stations as well as small base stations (e.g. Micro, Pico and Femto base stations). Such small base stations are typically deployed within the umbrella of macro cell coverage as illustrated in Fig. 6. For details and a more comprehensive introduction of HetNet, readers may refer to [92-98]. More specifically, studies on different aspects of the Pico and Femto cell deployments in LTE-Advanced networks can be found 
in [99-105] and [106-124] respectively. Small cells increase the capacity of the networks with an acceptable overall power consumption increase. Thus, HetNets are also interesting from an energy efficiency viewpoint, especially when power saving features like sleep mode are deployed [125-127].

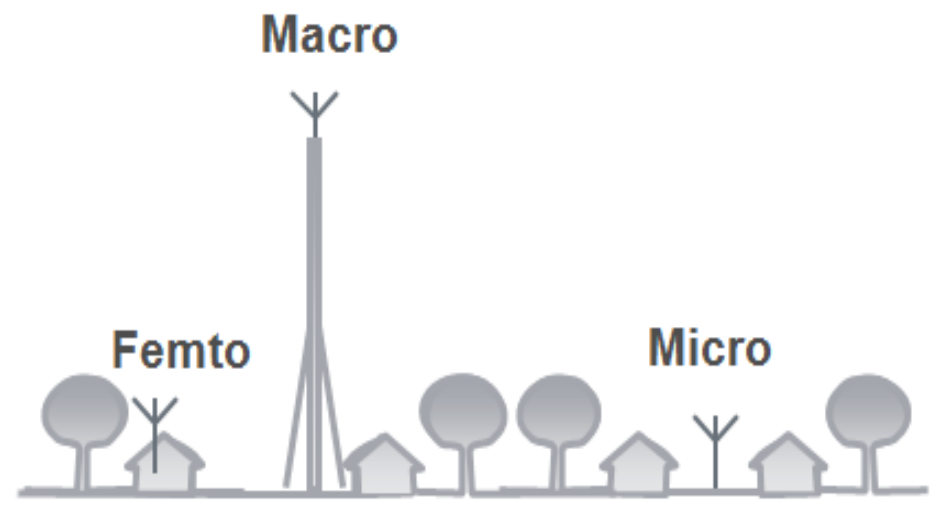

Fig. 6 Concept of HetNet

One of the main challenges in HetNet is to find suitable spectrums for small cells. Since all the available spectrum is usually assigned to the macro cells, different cell layers often have to use the same frequency [128]. This may cause interference issues which should be managed effectively in HetNets. Another concern is the amount of the traffic carried by the small cells. Typically, small cells have low output power and the received signal from small cells at UE is not strong enough, in comparison with macro cells, to attract enough users to the small cells.

\subsection{Technical Aspects}

Release 10 has come up with solutions to solve mentioned issues through a feature called enhanced Inter Cell Interference Coordination (eICIC), also referred to as Time Division Multiplexing ICIC (TDM-ICIC) $[102,129,130]$. In this feature, macro and small cells are coordinated in the time domain and inter cell interference is avoided by preventing simultaneous transmission. Time synchronisation among base stations is required for this feature and can be provided e.g. using GPS or IEEE 1588 phase sync. eICIC introduces muted sub-frames known as Almost Blank Subframe (ABS). ABSs are inserted to the macro cell frames, and the small cell uses these gaps to serve the UEs that are receiving strong signals from the macro cell, as seen in Fig. 7. The necessary information regarding ABS is exchanged between macro cell and small cell through the X2 interface. Having an ABS causes loss of the capacity of the network as it does not carry any user data. However, some information is still transmitted in ABS to provide backward compatibility for legacy UEs. Therefore, it does not offer full protection and still produces interference. More details about eICIC and its functionality can be found in [131-137]. Other methods to mitigate interference in LTE-Advanced heterogeneous networks are detailed in [138-148]. 


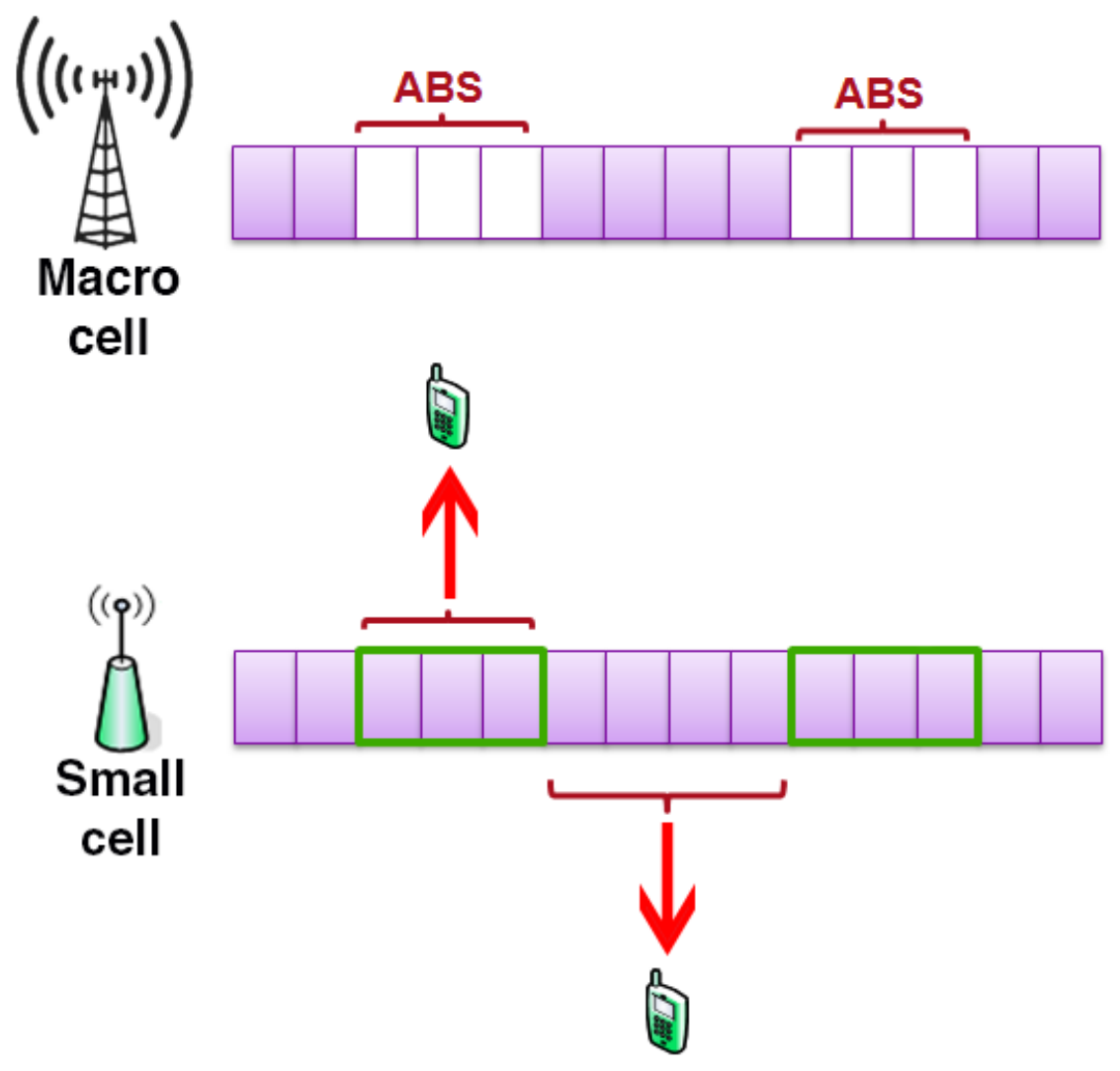

Fig. 7 eICIC functionality

Another issue in HetNet is that the small cells normally do not carry desirable amount of traffic as they typically have low output power. The footprint of the small cell can be extended in LTEAdvanced by modifying the mobility parameters under a feature called Range Extensions (RE). When $\mathrm{RE}$ is in place, positive offsets are applied to the small cell measurements and the UE will camp to it in worse radio conditions than without RE. Fig. 8 shows that RE increases the footprint of the small cell.

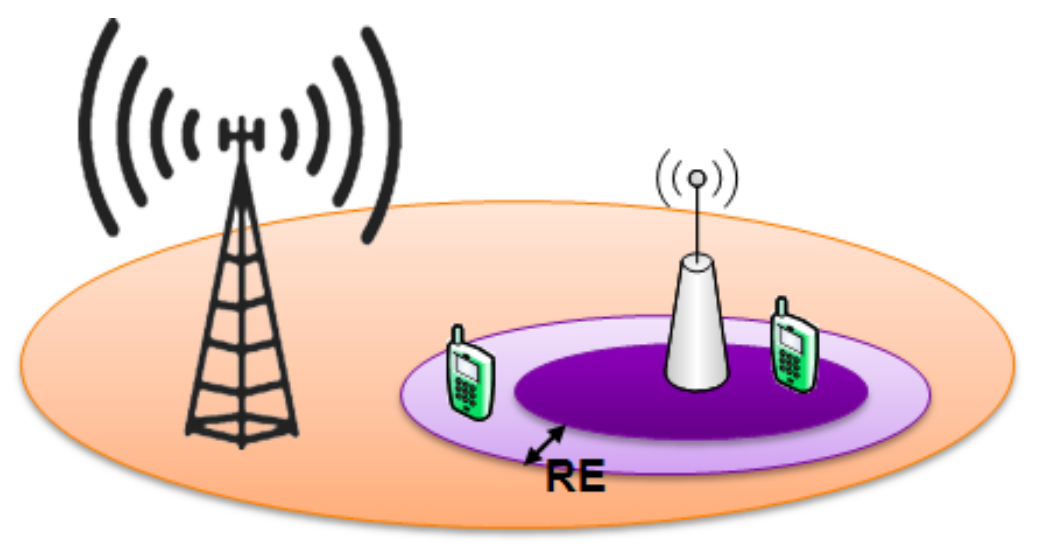

Fig. 8 Range Extension

However, it can result in a relatively bad performance in the UEs camped to the small cell, unless it is used together with interference mitigation features like eICIC. Without eICIC feature, these UEs receive strong interfering signals from the close-by macro cells. Hence, eICIC is one of the key features for enabling RE deployment in LTE-Advanced. Small cell's UEs in the RE area or cell edge 
may experience a high interference from the macro cell due to the co-channel deployment. The problem becomes more severe as the difference between macro and small cell transmit power increases. Having eICIC feature, larger RE values can be applied in the small cell. For more discussion, readers may refer to [149-153].

\section{$6 \quad$ Relaying}

\subsection{Overview}

Relay Node (RN) is a small site that operates between base station and UE. The main characteristic of the RN is that it does not need a separate backhaul and it is a self-backhauling base station. Relay nodes can be used in situations where providing backhaul is impractical or expensive. Installing RNs on mobile vehicles such as buses or in High Speed Railways (HSR) is another interesting application of the relays which is under consideration by 3 GPP and ITU [154,155]. RN can also be considered as a special case of the small cell deployment and RNs can be compared with Pico and Femto cells in terms of performance, cost and energy efficiency [156-158]. Like small cell, techniques such as interference coordination and range extension [159-163], and power control [164-168] are required for optimising the relaying network.

From the UE point of view, RN seems as a normal base station. From the base station viewpoint, relay acts as a UE with some special features, and core network considers RN as an additional sector for the base station. The intention of relaying is to increase data rates by reducing transmitter-to-receiver distance. The link between the relay node and the UE is referred to as the access link or Uu, and the link between the base station and relay node is referred to as the backhaul link or Un [169]. The architecture of the LTE-Advanced relaying network is shown in Fig. 9.

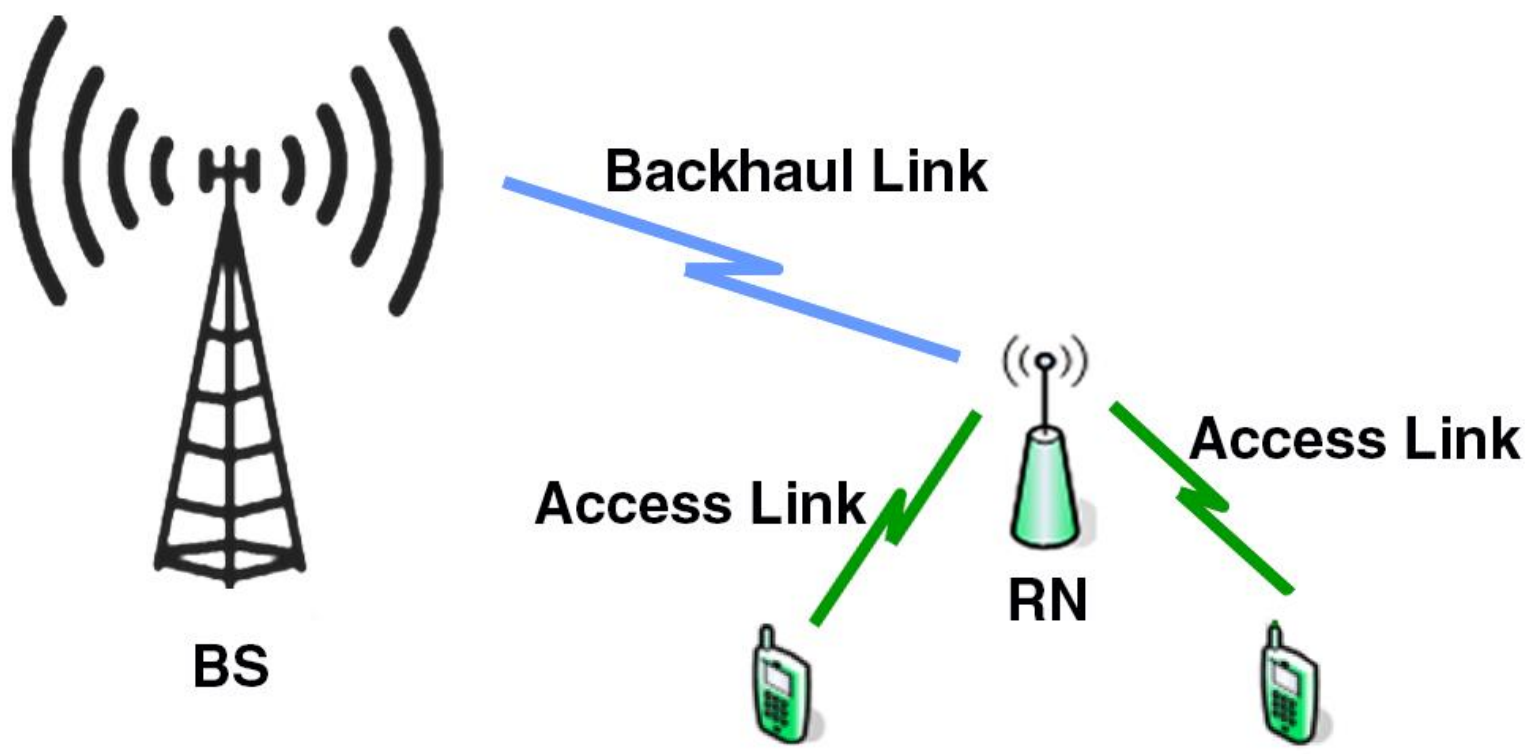

Fig. 9 RN deployment architecture

The access and backhaul links can use either Time Division Duplexing (TDD) or Frequency Division Duplexing (FDD) to distinguish between the uplink and downlink. Therefore, four links exist as illustrated in Fig. 10. In all cases, release 8 UEs are able to connect to the base station (donor cell), and backward compatibility is provided [170]. 


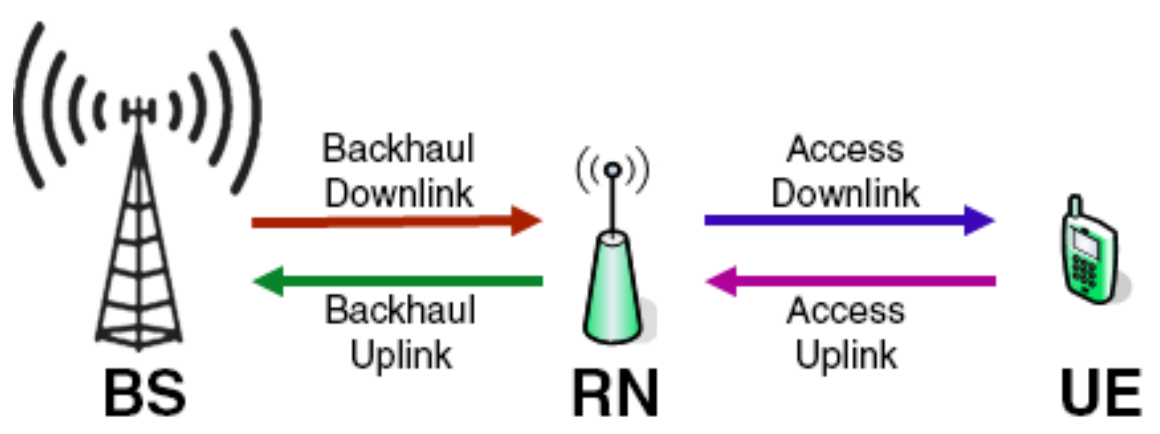

Fig. 10 RN four different links

If the split between the access link and the backhaul link is done in the frequency domain, the relay is called an outband relay. If the same frequency band is used for the both links and the split is done in the time domain, then it is called an inband relay. There are several studies for the appropriate resource sharing between backhaul and access links and mitigation of interference using the proper resource scheduling techniques [171-184]. CA feature can provide more flexible resource allocation in relaying networks $[185,186]$.

An RN is generally more intelligent than a repeater and can act as a base station. One of the advantages of the RN over repeater is that, the responsibility of delivering signals from RN to UE is with RN and base station will be freed up immediately after delivering the signal to the RN. Repeaters are amplifying whatever they receive and hence, they amplify the noise and interference as well. Some studies have been done concerning the deployment of the repeaters in LTE-Advanced networks $[187,188]$.

Relays can be categorised into transparent and non-transparent. In transparent relaying, the UE is not aware of the existence of the RN. In this case, the RN does not have a unique cell identity (Cell ID) and at least some parts of the Radio Resource Management (RRM) are done in donor base station. Hence, it is not creating a new cell in the network. In non-transparent relaying, RN has its own Cell ID and UE can distinguish whether it is connected to donor cell or the RN.

Relays can perform in two modes: Decode-and-Forward (DF) relay and Amplify-and-Forward (AF) relay. If the relay decodes and re-encodes the received signal before sending it to the receiver, it is known as the DF relay. In case the relay just amplifies and forwards the received signals, it is referred to as the AF relay. The performances of the DF and AF relays were compared in [189-191] and concluded that DF relays are more suitable for the LTE-Advanced system. The following types of DF, namely Layer 3 (L3) relays, can be categorised as [192]:

- Type 1a: It is a non-transparent outband relay and uses different frequencies in access and backhaul links. The implementation of this type of relays is easy and has little impacts on the network topology.

- Type $1 \mathrm{~b}$ : In this type, adequate isolation between access and backhaul antennas is provided, thus no split between the two links is needed. It is considered as inband relay, as the access and backhaul links use the same frequency. Its implementation is easy and almost same as type 1a. It is a non-transparent relay.

- Type 1: it is a non-transparent inband relay and uses the same frequency for access and backhaul links. Therefore, time division multiplexing of the links is required. Some changes should be made in the frame structures for implementing this type of the relay.

- Type 2: it is a transparent inband relay. It is not considered in release 10. This type of the RN would be used mainly in CoMP scenarios [193].

\subsection{Technical Aspects}

General performance analysis and system architecture of the relay-enhanced LTE-Advanced network is presented in [194-200]. Network planning in LTE-Advanced relaying networks is one of the challenging areas that still has several open research problems e.g. finding the optimum RNs placement methods. One such method is Enhanced tree (E-Tree) algorithm [201] in which the 
coverage problem is formulated based on Integer Linear Programming (ILP). By using E-tree algorithm, both elements of the two-hop relaying networks would be placed at the location which has the lowest construction cost. Hence, this technique is suitable for large scale network planning where the cost efficiency is an important issue, and it can help undeveloped countries to implement the infrastructures with lower time complexity and less construction cost. Some other methods and strategies regarding the site planning and RN placement were introduced in [202-205]. The effects of the antenna height on the propagation channel in relaying were also discussed in [206,207].

Deployment of RNs brings many benefits such as coverage, capacity and cell edge throughput enhancements to the LTE-Advanced network [208,209]. At the expense of deployment cost $[210,211]$, achievable gains in relaying networks substantially depend on the location and number of deployed relay nodes. In [212], three scenarios were proposed based on the number of relays per cell (RPC), and network performance was evaluated using Monte-Carlo simulation. The results show that two relays-per-cell can lead to a good compromise between capacity improvements and cost, while in three relays-per-cell scenario achieved gains cannot justify the cost in comparison with two relaysper-cell scenarios. Also, it can be seen that best performance is obtained in six relays-per-cell scenario. But it should be considered that the deployment of more relays per cell will significantly increase the implementation cost.

System performance evaluations by deploying RNs in LTE-Advanced systems have been performed in indoor [213], urban [214], and suburban [215,216] deployments. An evaluation has been done in an LTE-Advanced network in London, UK and the downlink channels performance of RNs was compared with the use of micro base stations [217]. In this study, inband relay was considered and the user data rate of $1024 \mathrm{kbps}$ was set as the minimum target. The results illustrate that in order to enhance network coverage and remove the coverage gaps, inband RNs are good choices. But they do not offer a desirable improvement in terms of network capacity due to the limitation of wireless backhaul links. It can be seen from the results of this study that micro site deployment can boost capacity of the network up to 5 times, without any degradation in the network footprint.

Another important aspect of the relaying network is the energy efficiency [218-221]. RN deployment can bring power savings in the uplink, and prolonging battery lifetime of the UE. The theoretical analysis and computer simulation results on effects of relaying by considering fixed RNs show that for the path-loss index of 4, power reduction of more than $50 \%$ ( 4 to $5 \mathrm{~dB}$ ) can be achieved [222]. The simulation shows high power efficiency achievement while maintaining an acceptable level of signal to noise ratio (SNR). Also, it was discussed that the optimum number of relays in terms of energy minimisation would be 12-24 per cell.

The increasing number of RNs increases interference between nodes. In addition, a new interference can be seen in relaying networks between the access link of an RN and backhaul link of another RN, which is referred to as relay-to-relay interference and addressed in [223]. Optimising the transmit power of the UE is an effective way to defeat the interference problem in relaying system. Reference [224] is discussed whether current employed power control parameters in LTE release 8 can be applied to both RN and base station in the LTE-Advanced relaying network. As predicted, deployment of relays even with current parameter settings shows a great enhancement in system performance. However, it is shown that it is not the best possible performance and better performance and more improvements can be achieved by optimising the relevant power control parameters.

Optimising output power and bandwidth allocation in relaying networks, considering type 1 relays are investigated in $[225,226]$. It is shown that deploying the bandwidth sharing method in LTE-Advanced networks can provide about $3.5 \mathrm{~dB}$ gain in the transmit power in comparison with the case in which fixed bandwidth is allocated. This considerable achieved gain can be used to increase coverage area, and provide a new way to enhance LTE-Advanced systems by deploying type 1 relays.

More advanced deployments of the relays such as cognitive relays [227], self-organising relays [228,229] coordinated/cooperative relay systems [230-233], and opportunistic relaying [234] have been studied and are expected to be used in future mobile communications networks. 


\section{CoMP Transmission and Reception}

\subsection{Overview}

This framework offers different techniques for having tight coordination between multiple locally distant radio access network nodes such as base stations and RNs. The coordination can be among the cells served by the same base station (intra base station), or the cells served by different base stations (inter base station). The synchronisation between base stations is obviously a necessity for having CoMP. In the case of inter base station CoMP, this synchronisation and coordination would be realised via the $\mathrm{X} 2$ interface between the base stations. CoMP was supposed to be considered as part of the Release 10 at the beginning, but due to the complexity and unclear realistic gain it was excluded later and moved to release 11 and beyond.

The idea of CoMP is that data will be sent (downlink) or received (uplink) not only by one cell, but by multiple cells and base stations. At the first sight, it looks the same as the soft and softer handover in $3 \mathrm{G}$ systems but CoMP is more intelligent and can make the channel adaptation very faster. As discussed in [235], CoMP and soft handover can be deployed together and provide more enhancements in LTE-Advanced networks. In some cases, CoMP can be considered as a kind of MIMO, namely multi-cell MIMO, in which the antennas are located at the different base stations. Deploying CoMP provides higher cell edge and average data rate in LTE-Advanced networks [236242], and also can bring considerable gains and improvements in HetNets [243-249].

\subsection{Technical Aspects}

Theoretically, two different versions of CoMP exist [250]. The simpler version is Coordinated Scheduling/Beamforming (CS/CB) in which the transmission is only done by one cell and the interference is minimised by coordination and proper scheduling among the surrounding cells. The more advanced CoMP is Joint Processing (JP) that also known as Cooperative MIMO (C-MIMO). In $\mathrm{JP}$, multiple cells are involved in transmission and they are coordinated for active interference cancelation. Consequently, the interference is converted to a useful signal and theoretical channel capacity (Shannon Limit) is increased. In general, JP brings more system improvements that CS/CB [251]. User-plane transmission in JP can be done either from multiple points at a time (Joint Transmission) or one point at a time (Dynamic Cell Selection). The latter is also known as Transmission Point Selection (TPS). Different CoMP deployment architectures are illustrated in Fig. $11[252]$.

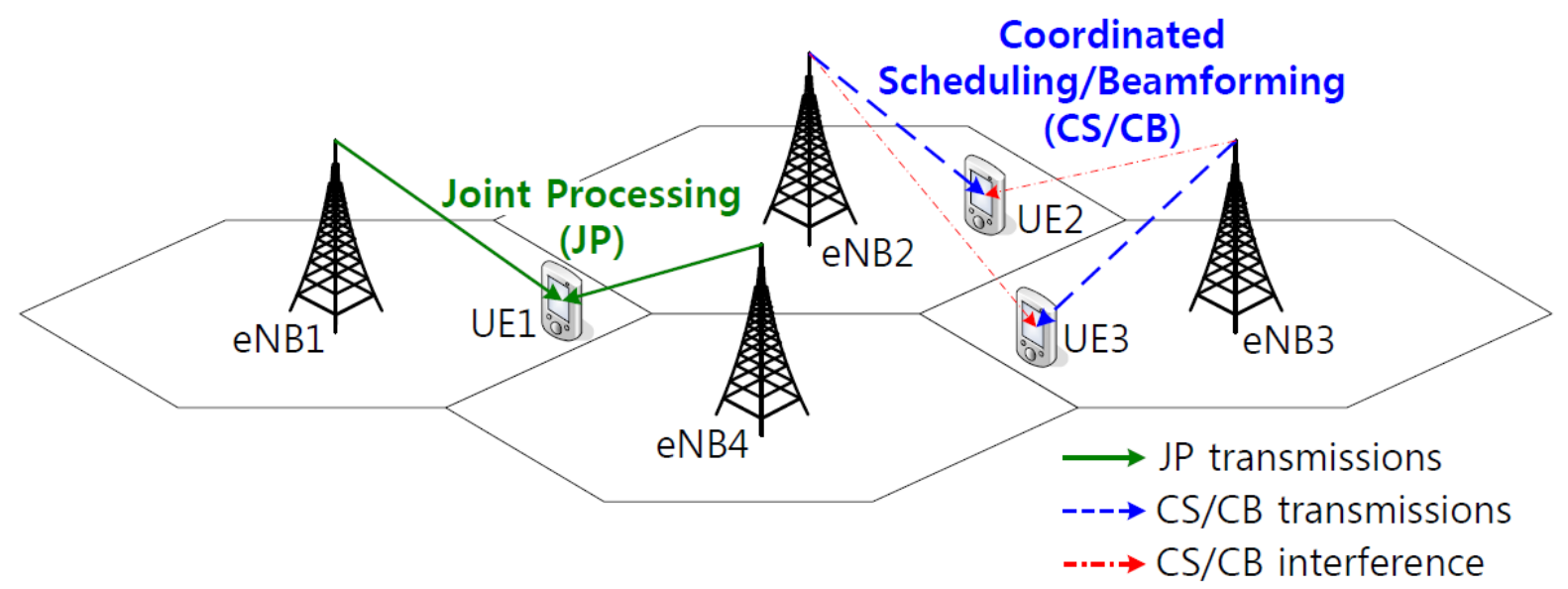

Fig. 11 CoMP architectures [252]

CoMP deployment can also result in energy savings in LTE-Advanced networks [253]. The energy savings gains can be boosted using the technique introduced in [254]. In this framework, power consumption of the network is reduced by toggling the transmission points between sleep and active modes based on their traffic. 
There are some practical challenges in using this feature; In order to have an efficient transmission in the downlink, the UE should be able to estimate the channel fading not only from the serving cell but also from the other cells involved in CoMP transmission. This is more challenging when the received signal undergoes excessive fading and is relatively weak. In addition, excessive overheads and delays would be caused when all these measurements are sent to the network as feedbacks. A method for reducing these feedbacks and system overheads is proposed in [255].

\section{Simulation results}

\subsection{Scenarios and results}

In this article, typical LTE and LTE-Advanced scenarios with one base station and one UE are defined and downlink data throughputs of the user are simulated for different Signal to Noise Ratio (SNR) values. The general simulation parameters for all the LTE and LTE-Advanced cases are set according to the 3GPP specifications, and key parameters are summarised in Table 7.

Table 7 General simulation parameters

\begin{tabular}{|c|c|}
\hline Parameter & Value \\
\hline Carrier Frequency & $2.5 \mathrm{GHz}$ \\
\hline Max No. of HARQ Retransmissions & 3 \\
\hline Cyclic Prefix & Normal \\
\hline Channel Type & Flat Rayleigh \\
\hline UE Channel Estimation Method & Perfect \\
\hline Number of Simulated Subframes & 800 \\
\hline
\end{tabular}

Firstly, four moderate cases are simulated for both LTE and LTE-Advanced. The UE is assumed to have two receiving antennas which is currently the case in almost all the practical situations. The results, shown in Fig.12 and Fig.13, are for two different bandwidths and MIMO configurations. Table 8 summarises the key simulation parameters for these cases.

Table 8 Simulation parameters used for Fig. 12 \& 13

\begin{tabular}{|c|c|}
\hline Parameter & Value \\
\hline CQI & 7 \\
\hline Modulation & $16 \mathrm{QAM}$ \\
\hline Bandwidth & $10 \mathrm{MHz}$ \\
& $20 \mathrm{MHz}$ \\
\hline MIMO & $4 \times 2$, Open Loop Spatial Multiplexing (OLSM) \\
\hline
\end{tabular}




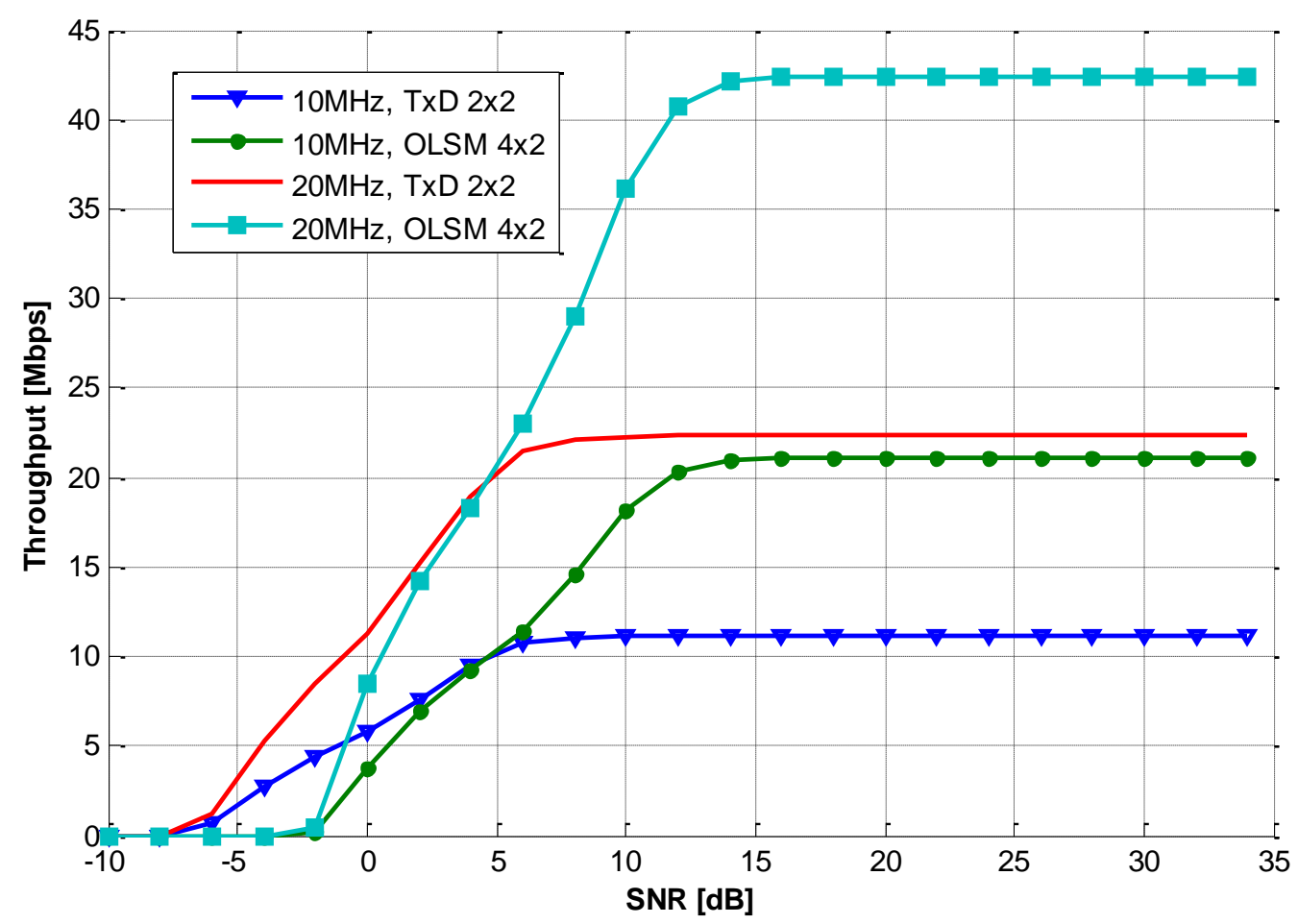

Fig. 12 LTE Simulation Results

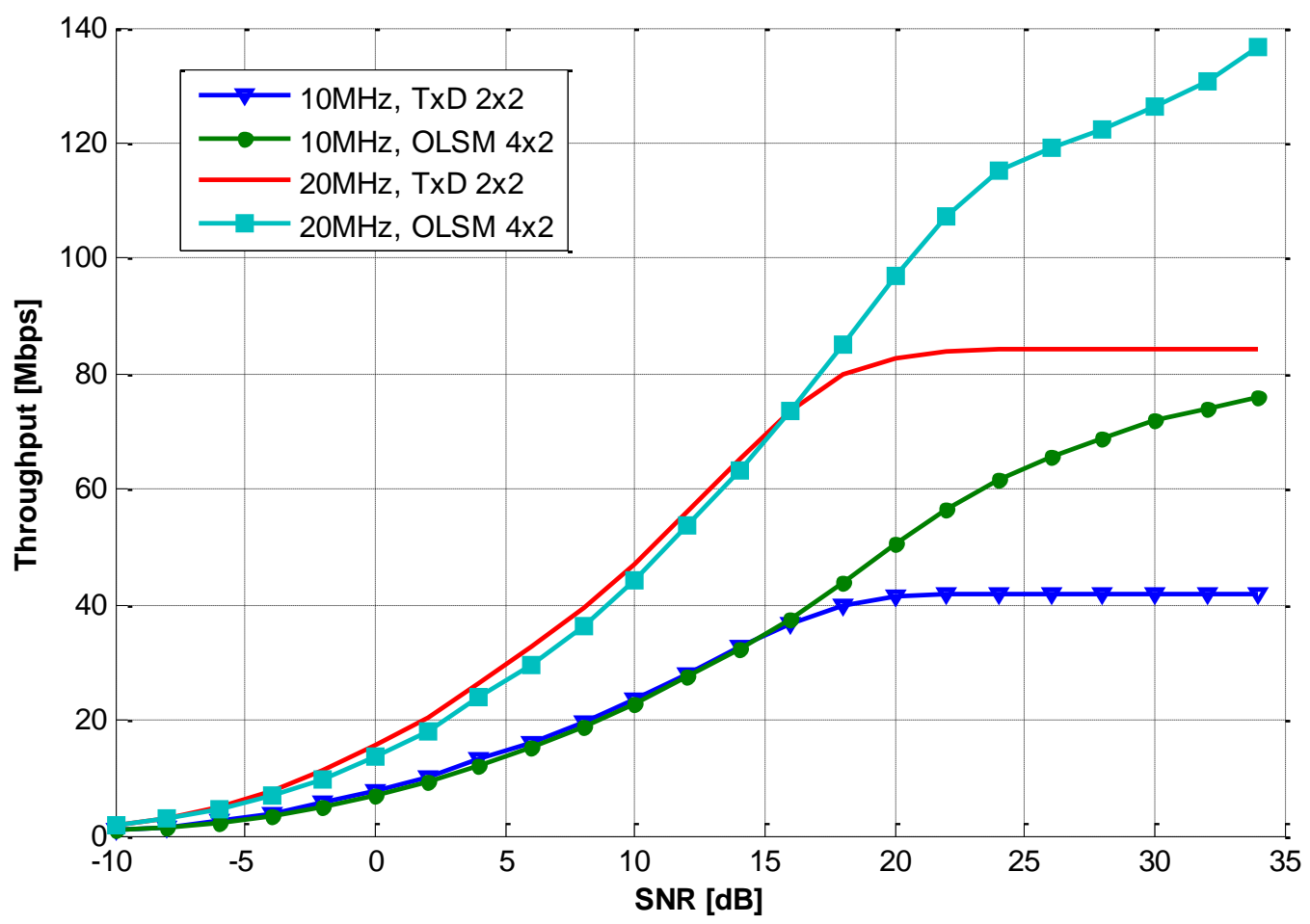

Fig. 13 LTE-Advanced Simulation Results 
Secondly, for better illustration of the LTE-Advanced capabilities, a few more cases are defined (summarised in Table 9) and simulated using the system level simulation. In these cases, the highest CQI value is used (i.e. 15), the base station has eight transmission antennas, and the MIMO operation is in the Closed Loop Spatial Multiplexing (CLSM) mode. Simulation results are presented in Fig. 14.

Table 9 Simulation parameters used for Fig. 14

\begin{tabular}{|c|c|}
\hline Parameter & Value \\
\hline CQI & 15 \\
\hline Modulation & $64 \mathrm{QAM}$ \\
\hline Bandwidth & $20 \mathrm{MHz}$ \\
\hline & $8 \times 2$ \\
\hline MIMO & $8 \times 4$ \\
& $8 \times 8$ \\
\hline
\end{tabular}

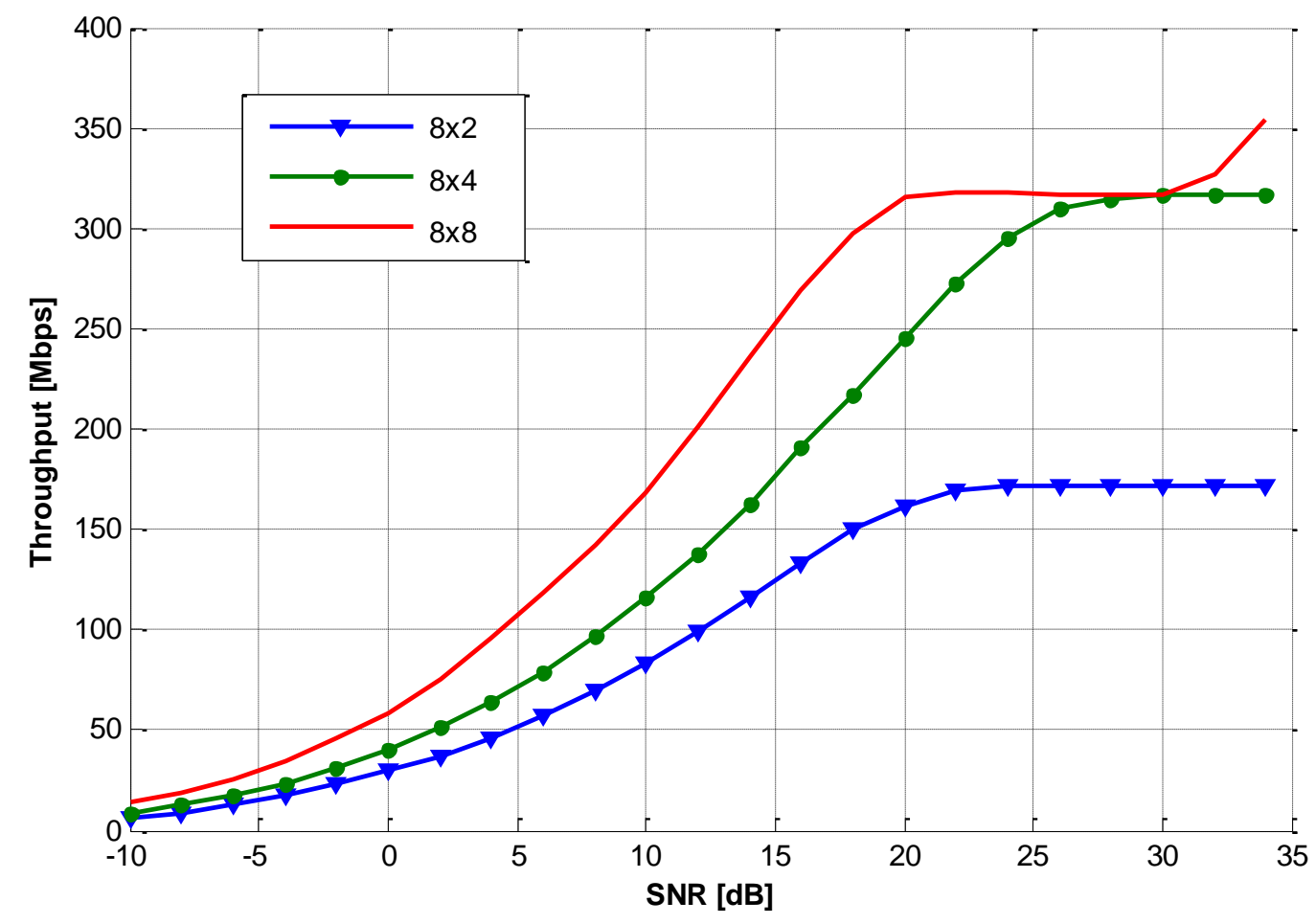

Fig. 14 LTE-Advanced simulation results

\subsection{Discussions on results}

The throughput can be achieved in LTE-Advanced, as illustrated in Fig. 14, is significant. The improvement in throughput from LTE to LTE-Advanced is quite visible from Fig. 12 and Fig. 13 and LTE-Advanced can be considered is a bold step towards meeting the fast-growing users' demands. It is seen that the advantages of LTE-Advanced over LTE are more substantial for higher SNR and any features that enhance the link quality can help to get more out of LTE-Advanced technology. The features discussed in this article add more enhancements in different aspects such as peak, average and cell edge data throughput and spectral efficiency. 


\section{Challenges and road map}

The actual data rate experienced by users are becoming at the centre of attention rather than the peak data rates. Despite all the improvements in LTE-Advanced system, cell-edge user data rate is far less than the peak data rate and the difference between cell-edge and peak data rates is still too high. The actual data throughputs are currently limited by inter-cell interference and dramatically depend on the link quality. Although frequency reuse-1 systems like LTE and LTE-Advanced are highly efficient in terms of overall efficiency, they suffer from high inter-cell interference at the cell boundaries. Hence, more developments on the interference management features like eICIC and CoMP transmission and reception are necessary. Furthermore, more enhancements in the small cell deployments are needed as they can improve the radio link quality of the users.

The first commercial LTE-Advanced network launched in October 2012 although no LTE-Advanced UE was available at the time. After releasing the first LTE-Advanced chipset in June 2013, several mobile network operators such as SK Telecom and LG Uplus have started to offer LTE-Advanced services to their customers. However, according to the current trends, LTE-Advanced systems are less likely to appear as the mainstream in the markets before 2016.

While 3GPP focuses on the release 12 finalisation, the release 13 study items are getting together and as of now a few items such as Radio Access Network (RAN) sharing enhancements have been set. On the other hand, studies on the beyond-LTE-Advanced systems for the future wireless mobile communications networks - known as $5 \mathrm{G}$ have already started. Considering the previous trends and the timeframe between the generations, 5G is predicted to be in the picture by 2020 and LTEadvanced technology would have to compete with it as well.

ITU-R estimations show that at least $1280 \mathrm{MHz}$ of spectrum bandwidth are required for the future development of IMT-2000 and IMT-Advanced by the year 2020 [256]. The required bandwidth can be provided by allocating new spectrums in higher frequency bands to the cellular networks. This may bring new challenges due to the special characteristic of the shorter wavelength signals. Another solution for dealing with the spectrum scarcity issues is to use Cognitive Radio (CR) technology in the networks in order to enable terminals to opportunistically access the spectrums which are being underutilised. CR technology offers flexible and efficient usage of the existing spectrum bandwidth and CR deployment seems inevitable for further evolution of LTE-Advanced networks. It will also play a more important role in $5 \mathrm{G}$ systems.

\section{Conclusion}

Five key features in LTE-Advanced systems are discussed in this article. Each of them brings some advantages to the wireless mobile networks for both operators and users. CA can provide higher peak data rate and cell edge user experience improvements. MIMO enhancement techniques do the same as well as average data rate enhancement, depending on the MIMO configurations and methods. CoMP transmission and reception can improve coverage in noise limited scenarios. HetNet enhances average and cell edge data rates. Regarding the RNs, their achievements depend on the situation they are deployed in. For instance, they can provide coverage for some locations that other kinds of base station cannot do, and therefore come up with a huge gain. These features are likely to be enhanced further and considered in future 3GPP releases and future wireless mobile technologies.

Acknowledgements The research leading to these results was partially derived from the University of Greenwich Research \& Enterprise Investment Programme grant under agreement number RAE-ES-01/14. The simulations results presented in this article have been generated using Vienna LTE-Advanced Link Level Simulator and Vienna LTE Link Level Simulator provided by the Institute of Telecommunications, Vienna University of Technology, Austria.

\section{References}

1. Cisco, "Cisco Visual Networking Index: Global Mobile Data Traffic Forecast Update, 2012-2017," Cisco white paper, 2013.

2. Ericsson, "Ericsson Mobility Report," June 2013.

3. GSA, "Evolution to LTE Report," Global mobile Suppliers Association, July 2014.

4. ITU-R M.2134, "Requirements related to technical performance for IMT-Advanced radio interface(s)," 2008. 
5. S. Parkvall, A. Furuskar and E. Dahlman, "Evolution of LTE toward IMT-advanced," IEEE Communications Magazine, vol. 49, no. 2, pp. 84 - 91, 2011.

6. A. GHOSH, R. RATASUK, B. MONDAL, N. MANGALVEDHE and M. THOMAS, "LTE-advanced: next-generation wireless broadband technology," IEEE Wireless Communication, vol. 17, no. 3, pp. 10-22, 2010.

7. P. Bhat, S. Nagata, L. Campoy, I. Berberana, T. Derham, G. Liu, X. Shen, P. Zong and J. Yang, "LTE-advanced: an operator perspective," IEEE Communications Magazine, vol. 50, no. 2, pp. 104-114, 2012.

8. D. Bai, C. Park, J. Lee, H. Nguyen, J. Singh, A. Gupta, Z. Pi, T. Kim, C. Lim, M.-G. Kim and I. Kang, "LTE-advanced modem design: challenges and perspectives," IEEE Communications Magazine, vol. 50, no. 2, pp. 178 - 186, 2012.

9. V. Stencel, A. Muller and P. Frank, "LTE Advanced - A further evolutionary step for Next Generation Mobile Networks," in 20th International Conference Radioelektronika (RADIOELEKTRONIKA), Brno, 2010.

10. M. Kiiski, "LTE-Advanced: The mainstream in mobile broadband evolution," in European Wireless Conference (EW), Lucca, 2010.

11. P. Mogensen, T. Koivisto, K. Pedersen, I. Kovacs, B. Raaf, K. Pajukoski and M. Rinne, "LTE-Advanced: The path towards gigabit/s in wireless mobile communications," in 1st International Conference on Wireless Communication, Vehicular Technology, Information Theory and Aerospace \& Electronic Systems Technology, Aalborg, 2009.

12. S. Parkvall, E. Englund, A. Furuskar, E. Dahlman, T. Jönsson and A. Paravati, "LTE evolution towards IMT-advanced and commercial network performance," in IEEE International Conference on Communication Systems (ICCS), Singapore, 2010.

13. S. Parkvall, E. Dahlman, A. Furuskar, Y. Jading, M. Olsson, S. Wanstedt and K. Zangi, "LTE-Advanced - Evolving LTE towards IMT-Advanced," in IEEE 68th Vehicular Technology Conference, Calgary, BC, 2008.

14. 3GPP TR 36.913, "Requirements for Further Advancements for Evolved Universal Terrestrial Radio Access (EUTRA) (LTE-Advanced)," 3rd Generation Partnership Project (3GPP).

15. 3GPP TS 36.306, "LTE; Evolved Universal Terrestrial Radio Access (E-UTRA); User Equipment (UE) radio access capabilities," 3rd Generation Partnership Project (3GPP).

16. Rohde \& Schwarz, "LTE / LTE-Advanced Technology Update," in LTE-Advanced Seminar, Fleet, 2013.

17. Y. Kakishima, T. Kawamura, Y. Kishiyama, H. Taoka and T. Nakamura, "Experimental Evaluation on Throughput Performance of Asymmetric Carrier Aggregation in LTE-Advanced," in IEEE 73rd Vehicular Technology Conference (VTC Spring), Yokohama, 2011.

18. K. Saito, Y. Kakishima, T. Kawamura, Y. Kishiyama, H. Taoka and H. Andoh, "Field experiments on throughput performance of carrier aggregation with asymmetric bandwidth in LTE-advanced," in Future Network \& Mobile Summit (FutureNetw), Berlin, 2012.

19. Z. Shen, A. Papasakellariou, J. Montojo, D. Gerstenberger and F. Xu, "Overview of 3GPP LTE-advanced carrier aggregation for 4G wireless communications," IEEE Communications Magazine, vol. 50, no. 2, pp. 122 - 130, 2012.

20. G. Yuan, X. Zhang, W. Wang and Y. Yang, "Carrier aggregation for LTE-advanced mobile communication systems," IEEE Communications Magazine, vol. 48, no. 2, pp. 88 - 93, 2010.

21. M. Iwamura, K. Etemad, M.-H. Fong, R. Nory and R. Love, "Carrier aggregation framework in 3GPP LTE-advanced [WiMAX/LTE Update],” IEEE Communications Magazine, vol. 48, no. 8, pp. 60 - 67, 2010.

22. K. Pedersen, F. Frederiksen, C. Rosa, H. Nguyen, L. Garcia and Y. Wang, "Carrier aggregation for LTE-advanced: functionality and performance aspects," IEEE Communications Magazine, vol. 49, no. 6, pp. 89 - 95, 2011.

23. M. Al-Shibly, M. Habaebi and J. Chebil, "Carrier aggregation in Long Term Evolution-Advanced," in IEEE Control and System Graduate Research Colloquium (ICSGRC), Shah Alam, Selangor, 2012.

24. R. Ratasuk, D. Tolli and A. Ghosh, "Carrier Aggregation in LTE-Advanced," in IEEE 71st Vehicular Technology Conference (VTC 2010-Spring), Taipei, 2010.

25. L. Chen, W. Chen, X. Zhang and D. Yang, "Analysis and Simulation for Spectrum Aggregation in LTE-Advanced System," in IEEE 70th Vehicular Technology Conference Fall, Anchorage, AK, 2009.

26. C. M. Park, H. B. Jung, S. H. Kim and D. K. Kim, "System level performance evaluation of various carrier aggregation scenarios in LTE-advanced," in 15th International Conference on Advanced Communication Technology (ICACT), PyeongChang, 2013.

27. I. Shayea, M. Ismail and R. Nordin, "Capacity evaluation of Carrier Aggregation techniques in LTE-Advanced system," in International Conference on Computer and Communication Engineering (ICCCE), Kuala Lumpur, 2012.

28. L. Liu, M. Li, J. Zhou, X. She, L. Chen, Y. Sagae and M. Iwamura, "Component Carrier Management for Carrier Aggregation in LTE-Advanced System," in IEEE 73rd Vehicular Technology Conference (VTC Spring), Budapest, 2011.

29. S. Gao, H. Tian, J. Zhu, L. Chen and X. She, "A throughput-optimized component carrier selection algorithm for LTEadvanced systems," in IET International Conference on Communication Technology and Application, Beijing, 2011.

30. C. Li, B. Wang, W. Wang, Y. Zhang and X. Chang, "Component carrier selection for LTE-A systems in diverse coverage carrier aggregation scenario," in IEEE 23rd International Symposium on Personal Indoor and Mobile Radio Communications (PIMRC), Sydney, NSW, 2012.

31. W.-C. Ho, L.-P. Tung, T.-S. Chang and K.-T. Feng, "Enhanced component carrier selection and power allocation in LTE-advanced downlink systems," in IEEE Wireless Communications and Networking Conference (WCNC), Shanghai, 2013.

32. H. Tian, S. Gao, J. Zhu and L. Chen, "Improved Component Carrier Selection Method for Non-Continuous Carrier Aggregation in LTE-Advanced Systems," in IEEE Vehicular Technology Conference (VTC Fall), San Francisco, CA, 2011.

33. Y. Wang, P. Chen, Q. Zhang and X. Lin, "Cross entropy based component carrier allocation in LTE-Advanced wireless communication system," in International Conference on Wireless Communications \& Signal Processing (WCSP), Huangshan, 2012. 
34. W. Qiu, H. Minn and C.-C. Chong, "Enhanced Frequency Diversity Exploitation in Carrier Aggregation for LTEAdvanced Systems," in IEEE Vehicular Technology Conference (VTC Fall), San Francisco, CA, 2011.

35. H. Wang, C. Rosa and K. Pedersen, "Uplink Component Carrier Selection for LTE-Advanced Systems with Carrier Aggregation," in IEEE International Conference on Communications (ICC), Kyoto, 2011.

36. H. Wang, C. Rosa and K. Pedersen, "Performance of Uplink Carrier Aggregation in LTE-Advanced Systems," in IEEE 72nd Vehicular Technology Conference Fall, Ottawa, ON, 2010.

37. L. Zhang, K. Zheng, W. Wang and L. Huang, "Performance analysis on carrier scheduling schemes in the long-term evolution-advanced system with carrier aggregation," IET Communications, vol. 5, no. 5, pp. 612 - 619, 2011.

38. Y. Wang, K. Pedersen, P. Mogensen and T. Sorensen, "Resource allocationconsiderations for multi-carrier LTEAdvanced systems operating in backward compatible mode," in IEEE 20th International Symposium on Personal, Indoor and Mobile Radio Communications, Tokyo, 2009.

39. H. Gao, J. Zhang, L. Zhang and J. Zhang, "Semi-JUS method for carrier aggregation in LTE-Advanced systems," in 3rd IEEE International Conference on Network Infrastructure and Digital Content (IC-NIDC), Beijing, 2012.

40. Z. Huang, Y. Ji and B. Zhao, "An efficient resource allocation algorithm with carrier aggregation in LTE Advanced systems," in International Conference on Wireless Communications \& Signal Processing (WCSP), Huangshan, 2012.

41. S. Songsong, F. Chunyan and G. Caili, "A Resource Scheduling Algorithm Based on User Grouping for LTE-Advanced System with Carrier Aggregation," in International Symposium on Computer Network and Multimedia Technology, Wuhan, 2009.

42. H. Wang, C. Rosa and K. Pedersen, "Performance Analysis of Downlink Inter-Band Carrier Aggregation in LTEAdvanced," in Vehicular Technology Conference, San Francisco, CA, 2011.

43. J. D. Naranjo, G. Bauch, A. B. Saleh, I. Viering and R. Halfmann, "A Dynamic Spectrum Access Scheme for an LTEAdvanced HetNet with Carrier Aggregation," in 9th International ITG Conference on Systems, Communication and Coding (SCC), Munich, 2013.

44. H. Holma and A. Toskala, LTE Advanced: 3GPP Solution for IMT-Advanced, Wiley, 2012.

45. P. W. Raut and S. Badjate, "MIMO-Future Wireless Communication," International Journal of Innovative Technology and Exploring Engineering (IJITEE), vol. 2, no. 5, pp. 102-106, 2013.

46. K. Werner, H. Asplund, D. Figueiredo, N. Jalden and B. Halvarsson, "LTE-advanced $8 \times 8$ MIMO measurements in an indoor scenario," in International Symposium on Antennas and Propagation (ISAP), Nagoys, 2012.

47. Y. Jing and Z. Zu-fan, "An 8-TX Diversity Scheme for LTE-A Downlink," in 6th International Conference on Wireless Communications Networking and Mobile Computing (WiCOM), Chengdu, 2010.

48. V. Kapinas and G. Karagiannidis, "A universal MIMO approach for 3GPP wireless standards," in IEEE Wireless Communications and Networking Conference (WCNC), Shanghai, 2012.

49. F. Boccardi, B. Clerckx, A. Ghosh, E. Hardouin, G. Jöngren, K. Kusume, E. Onggosanusi and Y. Tang, "Multipleantenna techniques in LTE-advanced," IEEE Communications Magazine, vol. 50, no. 3, pp. 114 - 121, 2012.

50. E. Lahetkangas, K. Pajukoski, E. Tiirola, J. Hamalainen and Z. Zheng, "On the performance of LTE-Advanced MIMO: How to set and reach beyond 4G targets," in 18th European Wireless Conference, Poznan, Poland, 2012.

51. H. Pennanen, T. Haataja, J. Leinonen, A. Tolli and M. Latva-aho, "System level evaluation of TDD based LTEAdvanced MIMO-OFDMA systems," in IEEE GLOBECOM Workshops (GC Wkshps), Miami, FL, 2010.

52. L. Liu, R. Chen, S. Geirhofer, K. Sayana, Z. Shi and Y. Zhou, " Downlink MIMO in LTE-advanced: SU-MIMO vs. MU-MIMO,” IEEE Communications Magazine, vol. 50, no. 2, pp. 140 - 147, 2012.

53. K. Kusume, G. Dietl, T. Abe, H. Taoka and S. Nagata, "System Level Performance of Downlink MU-MIMO Transmission for 3GPP LTE-Advanced," in IEEE 71st Vehicular Technology Conference (VTC 2010-Spring), Taipei, 2010.

54. Y. Kakishima, T. Kawamura, Y. Kishiyama, H. Taoka and H. Andoh, "Indoor Experiments on 4-by-2 Multi-User MIMO Employing Various Transmitter Antenna Arrangements in LTE-Advanced Downlink," in IEEE Vehicular Technology Conference (VTC Fall), Quebec City, QC, 2012.

55. K. Saito, Y. Kakishima, T. Kawamura, Y. Kishiyama, H. Taoka and H. Andoh, "Experimental Evaluations on 4-By-2 MU-MIMO Achieving 1 Gbps Throughput Using AMC with Outer-Loop Threshold Control for LTE-Advanced Downlink," in IEEE 75th Vehicular Technology Conference (VTC Spring), Yokohama, 2012.

56. Y. Kakishima, T. Kawamura, Y. Kishiyama, H. Taoka and H. Andoh, "Evaluating Downlink MU-MIMO: Laboratory Experimentation and Results," IEEE Vehicular Technology Magazine, vol. 7, no. 4, pp. 46 - 54, 2012.

57. B. Mondal, T. Thomas and A. Ghosh, "MU-MIMO system performance analysis in LTE evolution," in IEEE 21st International Symposium on Personal Indoor and Mobile Radio Communications (PIMRC), Instanbul, 2010.

58. C. Lim, T. Yoo, B. Clerckx, B. Lee and B. Shim, "Recent trend of multiuser MIMO in LTE-advanced," IEEE Communications Magazine, vol. 51, no. 3, pp. 127 - 135, 2013.

59. H.-L. Maattanen, T. Huovinen, T. Koivisto, M. Enescu, O. Tirkkonen and M. Valkama, "Performance Evaluations for Multiuser CQI Enhancements for LTE-Advanced," in IEEE 73rd Vehicular Technology Conference (VTC Spring), Yokohama, 2011.

60. W. J. Hwang, W. P. Kang, J. H. Jang and H. J. Choi, "A multi-user interference detection method for MU-MIMO transmission in LTE advanced system," in 18th Asia-Pacific Conference on Communications (APCC), Jeju Island, 2012

61. W. J. Hwang, J. H. Jang and H. J. Choi, " An enhanced channel estimation method for MU-MIMO based LTEAdvanced system," in 17th Asia-Pacific Conference on Communications (APCC), Sabah, 2011.

62. Z. Bai, B. Badic, S. Iwelski, R. Balraj, T. Scholand, G. Bruck and P. Jung, "Interference estimation for multi-layer MUMIMO transmission in LTE-Advanced systems," in IEEE 23rd International Symposium on Personal Indoor and Mobile Radio Communications (PIMRC), Sydney, NSW, 2012. 
63. R. Ghaffar, "LTE-Advanced Multi-User MIMO: Improved Feedback and Precoding Design," in IEEE Vehicular Technology Conference (VTC Fall), Quebec City, QC, 2012.

64. X. She, H. Taoka, J. Zhu and L. Chen, "Investigation of Control Signaling and Reference Signal Design for Downlink MU-MIMO in LTE-Advanced," in IEEE 73rd Vehicular Technology Conference (VTC Spring), Budapest, 2011.

65. D. Lu, H. Yang and K. Wu, "On the Feedback Enhancement and System Performance Evaluation of Downlink MUMIMO for 3GPP LTE-Advanced," in IEEE 73rd Vehicular Technology Conference (VTC Spring), Budapest, 2011.

66. Y. Dai, S. Jin, L. Jiang, X. Gao and M. Lei, "A PMI Feedback Scheme for Downlink Multi-User MIMO Based on Dual-Codebook of LTE-Advanced," in IEEE Vehicular Technology Conference (VTC Fall), Quebec City, QC, 2012.

67. G. Yue, N. Prasad and S. Rangarajan, "Downlink multiuser MIMO scheduling in LTE Advanced systems," in IEEE International Conference on Communications (ICC), Ottawa, ON, 2012.

68. M. Wang, F. Li, J. Evans and S. Dey, "Dynamic Multi-User MIMO scheduling with limited feedback in LTEAdvanced," in IEEE 23rd International Symposium on Personal Indoor and Mobile Radio Communications (PIMRC), Sydney, NSW, 2012.

69. P. Shang, X. Zhu, L. Zhang, J. Wu and J. Chen, "Delta Metric Scheduling for LTE-Advanced Uplink Multi-User MIMO Systems," in IEEE 75th Vehicular Technology Conference (VTC Spring), Yokohama, 2012.

70. J. Jin, C. Lin, Q. Wang, H. Yang and Y. Wang, "Effect of Imperfect Channel Estimation on Multi-User Beamforming in LTE-Advanced System," in IEEE 71st Vehicular Technology Conference (VTC 2010-Spring), Taipei, 2010.

71. L. Liu and J. Zhang, "New leakage-based iterative coordinated beam-forming for multi-user MIMO in LTEAdvanced," in IEEE International Conference on Communications (ICC), Ottawa, ON, 2012.

72. G. Yue, N. Prasad, M. Jiang, M. Khojastepour and S. Rangarajan, "Improving downlink multiuser MIMO throughput in LTE-advanced cellular systems," in IEEE 22nd International Symposium on Personal Indoor and Mobile Radio Communications (PIMRC), Toronto, ON, 2011.

73. H. T. Nguyen and I. Kovacs, "Downlink Radio Resource Management for LTE-Advanced System with Combined MUMIMO and Carrier Aggregation Features," in IEEE 75th Vehicular Technology Conference (VTC Spring), Yokohama, 2012.

74. Y. Kakishima, K. Takeda, T. Kawamura, Y. Kishiyama, H. Taoka and T. Nakamura, "Experimental evaluations on carrier aggregation and multi-user MIMO associated with EVD-based CSI feedback for LTE-Advanced downlink," in 8th International Symposium on Wireless Communication Systems (ISWCS), Aachen, 2011.

75. L. Zeng, J. Jin, Y. Wang and D. Yang, "A coordinated multi-cell MU-MIMO scheme for the downlink LTE-advanced system," in IEEE 20th International Symposium on Personal, Indoor and Mobile Radio Communications, Tokyo, 2009.

76. Y.-H. Nam, Y. Akimoto, Y. Kim, M.-i. Lee, K. Bhattad and A. Ekpenyong, "Evolution of reference signals for LTEadvanced systems," IEEE Communications Magazine, vol. 50, no. 2, pp. 132 - 138 , 2012.

77. T. Koivisto, K. Schober, T. Kuosmanen, T. Roman and M. Enescu, "Reference Signal Design for Flexible MIMO Operation in LTE-Advanced Downlink," in IEEE 71st Vehicular Technology Conference (VTC 2010-Spring), Taipei , 2010.

78. H. Wen, J. Luo, S. Zhang and Z. Zhang, "Adaptive design method for LTE-Advanced reference signals," in 5th International ICST Conference on Communications and Networking in China (CHINACOM), Beijing, 2010.

79. J. Wang, M. Wu and F. Zheng, "The Codebook Design for MIMO Precoding Systems in LTE and LTE-A," in 6th International Conference on Wireless Communications Networking and Mobile Computing (WiCOM), Chengdu, 2010.

80. T. Shuang, T. Koivisto, H.-L. Maattanen, K. Pietikainen, T. Roman and M. Enescu, "Design and Evaluation of LTEAdvanced Double Codebook," in IEEE 73rd Vehicular Technology Conference (VTC Spring), Yokohama, 2011.

81. Y. Yan, H. Yuan, N. Zheng and S. Peter, "Performance of uplink multi-user MIMO in LTE-advanced networks," in International Symposium on Wireless Communication Systems (ISWCS), ,Paris, 2012.

82. C. Park, Y.-P. Wang, G. Jöngren and D. Hammarwall, "Evolution of Uplink MIMO for LTE-Advanced," IEEE Communications agazine, vol. 49, no. 2, pp. 112-121, February 2011.

83. K. Banawan and E. Sourour, "C43. Combined Collaborative and Precoded MIMO for Uplink of the LTE-Advanced," in 29th National Radio Science Conference (NRSC), Cairo, 2012.

84. S. Yasukawa, T. Kawamura, Y. Kishiyama, H. Taoka and H. Andoh, "Field Experiments on Closed-Loop SU-MIMO Transmission Considering Effect of Antenna Configurations in LTE-Advanced Uplink," in IEEE 75th Vehicular Technology Conference (VTC Spring), Yokohama, 2012.

85. S. Yasukawa, T. Kawamura, Y. Kishiyama, H. Taoka and T. Nakamura, "Experimental Evaluation on SU-MIMO Transmission with Closed-Loop Precoding in LTE-Advanced Uplink," in IEEE 73rd Vehicular Technology Conference (VTC Spring), Yokohama, 2011.

86. A. Nishio, T. Iwai, A. Matsumoto and D. Imamura, "System Evaluation of MU-MIMO and Multi-Cluster Allocation in LTE-Advanced Uplink," in IEEE 75th Vehicular Technology Conference (VTC Spring), Yokohama, 2012.

87. O.-S. Park, D.-H. Kim and J.-M. Ahn, " Performance analysis of clustered DFT-Spread OFDM for LTE-Advanced uplink MIMO," in 4th International Conference on Signal Processing and Communication Systems (ICSPCS), Gold Coast, QLD , 2010 .

88. Y. Meng, G. Shen, J. Pang, W. Wang, F. Han and D. Wang, "Multi-Antenna Uplink Transmission for LTE-A," in IEEE Vehicular Technology Conference (VTC Fall), Quebec City, QC, 2012.

89. H. Wang, H. Nguyen, C. Rosa and K. Pedersen, "Uplink multi-cluster scheduling with MU-MIMO for LTE-Advanced with carrier aggregation," in IEEE Wireless Communications and Networking Conference (WCNC), Shanghai, 2012.

90. T. Iwai, A. Matsumoto, S. Takaoka, Y. Ogawa, A. Nishio and D. Imamura, "System Performance of Clustered DFT-SOFDM Considering Maximum Allowable Transmit Power," in IEEE International Conference on Communications (ICC), Kyoto, 2011.

91. J. Chen and X. Zhao, "An Adaptive MIMO Detection Approach for LTE Advanced Uplink," in IEEE 75th Vehicular Technology Conference (VTC Spring), Yokohama, 2012. 
92. A. Khandekar, N. Bhushan, J. Tingfang and V. Vanghi, "LTE-Advanced: Heterogeneous networks," in Wireless Conference (EW), Lucca, 2010.

93. S. Brueck, "Heterogeneous networks in LTE-Advanced," in 8th International Symposium on Wireless Communication Systems (ISWCS), Aachen, 2011.

94. W. Lei, W. Hai, Y. Yinghui and Z. Fei, "Heterogeneous network in LTE-advanced system," in IEEE International Conference on Communication Systems (ICCS), Singapore, 2010.

95. E. Bodanese, "A brief introduction to heterogeneous networks (HetNets) and its challenges," in IET International Conference on Communication Technology and Application, Beijing, 2011.

96. T. Hu, J. Pang and H.-J. Su, "LTE-Advanced heterogeneous networks: Release 10 and beyond," in IEEE International Conference on Communications (ICC), Ottawa, ON, 2012.

97. T. Nakamura, S. Nagata, A. Benjebbour, Y. Kishiyama, T. Hai, S. Xiaodong, Y. Ning and L. Nan, "Trends in small cell enhancements in LTE advanced," IEEE Communications Magazine, vol. 51, no. 2, pp. 98 - 105, 2013.

98. Y. Blankenship, "Achieving high capacity with small cells in LTE-A," in 50th Annual Allerton Conference on Communication, Control, and Computing (Allerton), Monticello, IL, 2012.

99. N. Lu, X. Zhu, Z. Jiang, X. Lu, F. Yang and Q. Bi, "Performance of LTE-Advanced macro-pico heterogeneous networks," in IEEE Wireless Communications and Networking Conference (WCNC), Shanghai, 2013.

100. P. Tian, H. Tian, L. Gao, J. Wang, X. She and L. Chen, "Deployment analysis and optimization of Macro-Pico heterogeneous networks in LTE-A system," in 15th International Symposium on Wireless Personal Multimedia Communications (WPMC), Taipei, 2012.

101. Y. Peng and F. Qin, "Exploring Het-Net in LTE-Advanced System: Interference Mitigation and Performance Improvement in Macro-Pico Scenario," in IEEE International Conference on Communications Workshops (ICC), Kyoto, 2011.

102. N. Miyazaki, X. Wang, M. Fushiki, Y. Akimoto and S. Konishi, "A Proposal for Radio Resource Allocation of TDM Inter-Cell Interference Coordination to Heterogeneous Networks with Pico Cells in LTE-Advanced," in IEEE Vehicular Technology Conference (VTC Fall), Quebec City, QC, 2012.

103. K. Kitagawa, T. Komine, T. Yamamoto and S. Konishi, "Performance evaluation of handover in LTE-Advanced systems with pico cell Range Expansion," in IEEE 23rd International Symposium on Personal Indoor and Mobile Radio Communications (PIMRC), Sydney, NSW, 2012.

104. K. Okino, T. Nakayama, C. Yamazaki, H. Sato and Y. Kusano, "Pico Cell Range Expansion with Interference Mitigation toward LTE-Advanced Heterogeneous Networks," in IEEE International Conference on Communications Workshops (ICC), Kyoto, 2011.

105. B. A. Yasir, G. Su and N. Bachache, "Range expansion for pico cell in heterogeneous LTE - A cellular networks," in 2nd International Conference on Computer Science and Network Technology (ICCSNT), Changchun, China, 2012.

106. M. Khan, M. Khan and K. Raahemifar, "A study of femtocell architectures for long term evolution (LTE)-advanced network," in 24th Canadian Conference on Electrical and Computer Engineering (CCECE), Niagara Falls, ON, 2011.

107. I. Shgluof, M. Ismail and R. Nordin, "Efficient femtocell deployment under macrocell coverage in LTE-Advanced system," in International Conference on Computing, Management and Telecommunications (ComManTel), Ho Chi Minh City, Vietnam, 2013.

108. A. Szufarska, K. Safjan, K. Pedersen, F. Frederiksen and F. Frederiksen, "Interference Mitigation Methods for LTEAdvanced Networks with Macro and HeNB Deployments," in IEEE Vehicular Technology Conference (VTC Fall), San Francisco, CA, 2011.

109. L. Saker, S. Elayoubi and T. Chahed, "How femtocells impact the capacity and the energy efficiency of LTE-Advanced networks," in IEEE 22nd International Symposium on Personal Indoor and Mobile Radio Communications (PIMRC), Toronto, ON, 2011.

110. C. Bouras, G. Diles, V. Kokkinos and A. Papazois, "Power management over co-channel femtocells in LTE-A systems," in IFIP Wireless Days (WD), Dublin, 2012.

111. J. Kim, H. Kim, K. Cho and N. Park, "SON and Femtocell Technology for LTE-Advanced System," in 6th International Conference on Wireless and Mobile Communications (ICWMC), Valencia, 2010.

112. C. Herranz, V. Osa, J. Monserrat, D. Calabuig, N. Cardona and X. Gelabert, "Cognitive Radio enabling opportunistic spectrum access in LTE-Advanced femtocells," in IEEE International Conference on Communications (ICC), Ottawa, ON, 2012.

113. S. Wang, J. Wang, J. Xu, Y. Teng and K. Horneman, "Cooperative component carrier (Re-)selection for LTE-advanced femtocells," in IEEE Wireless Communications and Networking Conference (WCNC), Cancun, Quintana Roo, 2011.

114. W.-c. Hong and Z. Tsai, "Improving the autonomous component carrier selection for home eNodeBs in LTEAdvanced," in IEEE Consumer Communications and Networking Conference (CCNC), Las Vegas, NV, 2011.

115. L. Garcia, F. Sanchez-Moya, J. Villalba-Espinosa, K. Pedersen and P. Mogensen, "Enhanced Uplink Carrier Aggregation for LTE-Advanced Femtocells," in IEEE Vehicular Technology Conference (VTC Fall), San Francisco, CA, 2011.

116. K. Zheng, F. Hu, L. Lei and W. Wang, "Interference coordination between femtocells in LTE-advanced networks with carrier aggregation," in 5th International ICST Conference on Communications and Networking in China (CHINACOM), Beijing, 2010.

117. Y. Lei and Y. Zhang, "Enhanced mobility state detection based mobility optimization for FEMTO cells in LTE and LTE-Advanced networks," in IET International Conference on Communication Technology and Application, Beijing, 2011.

118. H. Zhang, W. Ma, W. Li, W. Zheng, X. Wen and C. Jiang, "Signalling Cost Evaluation of Handover Management Schemes in LTE-Advanced Femtocell," in IEEE 73rd Vehicular Technology Conference (VTC Spring), Yokohama, 2011. 
119. S. Oh, H. Kim, B. Ryu and N. Park, "Inbound Mobility Management on LTE-Advanced Femtocell Topology Using X2 Interface," in 20th International Conference on Computer Communications and Networks (ICCCN), Maui, HI, 2011.

120. H. Zhang, W. Zheng, X. Wen and C. Jiang, "Signalling Overhead Evaluation of HeNB Mobility Enhanced Schemes in 3GPP LTE-Advanced," in IEEE 73rd Vehicular Technology Conference (VTC Spring), Yokohama, 2011.

121. R. Saha and P. Saengudomlert, "Novel resource scheduling for spectral efficiency in LTE-advanced systems with macrocells and femtocells," in 8th International Conference on Electrical Engineering/Electronics, Computer, Telecommunications and Information Technology (ECTI-CON), Khon Kaen, 2011.

122. L. Garcia, K. Pedersen and P. Mogensen, "Uplink Performance of Dynamic Interference Coordination under Fractional Power Control for LTE-Advanced Femtocells," in IEEE 72nd Vehicular Technology Conference Fall (VTC 2010-Fall), Ottawa, ON, 2010.

123. L. Garcia, K. Pedersen and P. Mogensen, "On Open versus Closed LTE-Advanced Femtocells and Dynamic Interference Coordination," in IEEE Wireless Communications and Networking Conference (WCNC), Sydney, Australia, 2010.

124. F. Hu, K. Zheng, L. Lei and W. Wang, "A Distributed Inter-Cell Interference Coordination Scheme between Femtocells in LTE-Advanced Networks," in IEEE 73rd Vehicular Technology Conference (VTC Spring), Yokohama, 2011.

125. C. Khirallah, J. Thompson and D. Vukobratovic, "Energy efficiency of heterogeneous networks in LTE-advanced," in IEEE Wireless Communications and Networking Conference Workshops (WCNCW), Paris, 2012.

126. L. Saker, S. Elayoubi, T. Chahed and A. Gati, "Energy efficiency and capacity of heterogeneous network deployment in LTE-Advanced," in 18th European Wireless Conference European Wireless, Poznan, Poland, 2012.

127. A. Prasad, O. Tirkkonen, P. Lunden, O. Yilmaz, L. Dalsgaard and C. Wijting, "Energy-efficient inter-frequency small cell discovery techniques for LTE-advanced heterogeneous network deployments," IEEE Communications Magazine, vol. 51, no. 5, pp. $72-81,2013$.

128. T. Zahir, K. Arshad, A. Nakata and K. Moessner, "Interference Management in Femtocells," IEEE Communications Surveys \& Tutorials, vol. 15, no. 1, pp. 293 - 311, 2013.

129. S. Kaneko, T. Matsunaka and Y. Kishi, "A Cell-Planning Model for HetNet with CRE and TDM-ICIC in LTEAdvanced," in IEEE 75th Vehicular Technology Conference (VTC Spring), Yokohama, 2012.

130. Q. Yang, D. Xiao and X. Jing, "Cell identification based on enhanced icic for heterogeneous networks in LTE-A systems," in IET International Conference on Communication Technology and Application, Beijing, 2011.

131. Y. Wu, D. Xiao, J. Cui and X. Luo, "An inter-cell interference coordination method in heterogeneous LTE-Advanced system," in World Congress on Information and Communication Technologies (WICT), Trivandrum, 2012.

132. K. Pedersen, Y. Wang, B. Soret and F. Frederiksen, "eICIC Functionality and Performance for LTE HetNet CoChannel Deployments," in IEEE Vehicular Technology Conference (VTC Fall), Quebec City, QC, 2012.

133. M. Kamel and K. Elsayed, "Performance evaluation of a coordinated time-domain eICIC framework based on ABSF in heterogeneous LTE-Advanced networks," in IEEE Global Communications Conference (GLOBECOM), Anaheim, CA, 2012.

134. Y. Wang and K. Pedersen, "Performance Analysis of Enhanced Inter-Cell Interference Coordination in LTE-Advanced Heterogeneous Networks," in IEEE 75th Vehicular Technology Conference (VTC Spring), Yokohama, 2012.

135. A. Weber and O. Stanze, "Scheduling strategies for HetNets using eICIC," in IEEE International Conference on Communications (ICC), Ottawa, ON, 2012.

136. B. Soret, H. Wang, K. Pedersen and C. Rosa, "Multicell cooperation for LTE-advanced heterogeneous network scenarios," IEEE Wireless Communications, vol. 20, no. 1, pp. 27 - 34, 2013.

137. A. Damnjanovic, J. Montojo, J. Cho, H. Ji, J. Yang and P. Zong, "UE's role in LTE advanced heterogeneous networks," IEEE Communications Magazine, vol. 50, no. 2, pp. 164 - 176, 2012.

138. B. Li, "An Effective Inter-Cell Interference Coordination," in IEEE 73rd Vehicular Technology Conference (VTC Spring), Yokohama, 2011.

139. J. Huang, P. Xiao and X. Jing, "A downlink ICIC method based on region in the LTE-Advanced system," in IEEE 21st International Symposium on Personal, Indoor and Mobile Radio Communications Workshops (PIMRC Workshops), Istanbul, 2010.

140. Q. Li, D. Xiao and D. Yang, "A downlink ICIC method based on priority in LTE-Advanced systems," in 4th IEEE International Conference on Broadband Network and Multimedia Technology (IC-BNMT), Shenzhen, 2011.

141. D. Xiao, X. Yu and D. Yang, "A Novel Downlink ICIC Method Based on User Position in LTE-Advanced Systems," in IEEE Vehicular Technology Conference (VTC Fall), Quebec City, QC, 2012.

142. J. Zhang, H. Tian, P. Tian, Y. Huang and L. Gao, "Dynamic Frequency Reservation Scheme for Interference Coordination in LTE-Advanced Heterogeneous Networks," in IEEE 75th Vehicular Technology Conference (VTC Spring), Yokohama, 2012.

143. N. Saquib, E. Hossain and D. I. Kim, "Fractional frequency reuse for interference management in LTE-advanced hetnets," IEEE Wireless Communications, vol. 20, no. 2, pp. 113 - 122, 2013.

144. Y. Li, M. Peng and W. Hu, "Adaptive heterogeneous interference coordination algorithm in uplink LTE-Advanced systems," in IEEE 23rd International Symposium on Personal Indoor and Mobile Radio Communications (PIMRC), Sydney, NSW, 2012.

145. G. Cao, D. Yang, X. Zhu and X. Zhang, "A joint resource allocation and power control algorithm for heterogeneous network," in 19th International Conference on Telecommunications (ICT), Jounieh, 2012.

146. S. Xu, J. Han and T. Chen, "Enhanced Inter-Cell Interference Coordination in Heterogeneous Networks for LTEAdvanced," in IEEE 75th Vehicular Technology Conference (VTC Spring), Yokohama, 2012.

147. D. Lopez-Perez, I. Guvenc, G. de la Roche, M. Kountouris, T. Quek and J. Zhang, "Enhanced intercell interference coordination challenges in heterogeneous networks," IEEE Wireless Communications, vol. 18, no. 3, pp. 22 - $30,2011$. 
148. J. Wang, X. She and L. Chen, "Enhanced Dynamic Inter-Cell Interference Coordination Schemes for LTE-Advanced," in IEEE 75th Vehicular Technology Conference (VTC Spring), Yokohama, 2012.

149. D. Luo, B. Li and D. Yang, "Performance Evaluation with Range Expansion for Heterogeneous Networks," in IEEE Vehicular Technology Conference (VTC Fall), San Francisco, CA, 2011.

150. J. Oh and Y. Han, "Cell selection for range expansion with almost blank subframe in heterogeneous networks," in IEEE 23rd International Symposium on Personal Indoor and Mobile Radio Communications (PIMRC), Sydney, NSW, 2012.

151. M. Shirakabe, A. Morimoto and N. Miki, "Performance evaluation of inter-cell interference coordination and cell range expansion in heterogeneous networks for LTE-Advanced downlink," in 8th International Symposium on Wireless Communication Systems (ISWCS), Aachen, 2011.

152. M. Al-Rawi, "A dynamic approach for cell range expansion in interference coordinated LTE-advanced heterogeneous networks," in IEEE International Conference on Communication Systems (ICCS), Singapore, 2012.

153. P. Tian, H. Tian, J. Zhu, L. Chen and X. She, "An adaptive bias configuration strategy for Range Extension in LTEAdvanced Heterogeneous Networks," in IET International Conference on Communication Technology and Application, Beijing, 2011.

154. W. Li, C. Zhang, X. Duan, S. Jia, Y. Liu and L. Zhang, "Performance Evaluation and Analysis on Group Mobility of Mobile Relay for LTE Advanced System," in IEEE Vehicular Technology Conference (VTC Fall), Quebec City, QC, 2012.

155. H. Lin, D. Gu, W. Wang and H. Yang, "Capacity analysis of dedicated fixed and mobile relay in LTE-Advanced cellular networks," in IEEE International Conference on Communications Technology and Applications, Beijing, 2009.

156. A. Saleh, S. Redana, B. Raaf and J. Hamalainen, "Comparison of Relay and Pico eNB Deployments in LTEAdvanced," in IEEE 70th Vehicular Technology Conference Fall, Anchorage, AK, 2009.

157. A. Saleh, O. Bulakci, S. Redana, B. Raaf and J. Hamalainen, "Evaluating the energy efficiency of LTE-Advanced relay and Picocell deployments," in IEEE Wireless Communications and Networking Conference (WCNC), Shanghai, 2012.

158. C. Khirallah, J. Thompson and H. Rashvand, "Energy and cost impacts of relay and femtocell deployments in longterm-evolution advanced," IET Communications, vol. 5, no. 18, pp. 2617 - 2628, 2011.

159. A. A. Rasheed and S. Wager, "Cell range extension in LTE in-band relays: Analysis of radio link, subframe allocation and protocol perfornance of FTP traffic model," in 18th European Wireless Conference, Poznan, Poland, 2012.

160. D. W. Kifle, O. Bulakci, A. B. Saleh, S. Redana and F. Granelli, "Joint backhaul co-scheduling and relay cell extension in LTE-advanced networks uplink performance evaluation," in 18th European Wireless Conference, Poznan, Poland, 2012.

161. Z. Ren, A. Saleh, O. Bulakci, S. Redana, B. Raaf and J. Hamalainen, "Joint interference coordination and relay cell expansion in LTE-Advanced networks," in IEEE Wireless Communications and Networking Conference (WCNC), Shanghai, 2012.

162. A. Saleh, O. Bulakci, S. Redana, B. Raaf and J. Hamalainen, "Enhancing LTE-advanced relay deployments via Biasing in cell selection and handover decision," in IEEE 21 st International Symposium on Personal Indoor and Mobile Radio Communications (PIMRC), Instanbul, 2010.

163. G. Liebl, T. de Moraes, A. Gonzalez Rodriguez and M. Nisar, "Centralized interference coordination in relay-enhanced networks," in IEEE Wireless Communications and Networking Conference Workshops (WCNCW), Paris, 2012.

164. O. Bulakci, S. Redana, B. Raaf and J. Hamalainen, "Impact of power control optimization on the system performance of relay based LTE-Advanced heterogeneous networks," Journal of Communications and Networks, vol. 13, no. 4, pp. $345-359,2011$.

165. O. Bulakci, A. Awada, A. Saleh, S. Redana, J. Hamalainen, B. Wegmann, B. Raaf and I. Viering, "Joint optimization of uplink power control parameters in LTE-Advanced relay networks," in 7th International Wireless Communications and Mobile Computing Conference (IWCMC), Istanbul, 2011.

166. O. Bulakci, S. Redana, B. Raaf and J. Hämäläinen, "System Optimization in Relay Enhanced LTE-Advanced Networks via Uplink Power Control," in IEEE 71st Vehicular Technology Conference (VTC 2010-Spring), Taipei, Taiwan, 2010.

167. O. Bulakci, A. Saleh, Z. Ren, S. Redana, B. Raaf and J. Hamalainen, "Two-step resource sharing and uplink power control optimization in LTE-Advanced relay networks," in 8th International Workshop on Multi-Carrier Systems \& Solutions (MC-SS), Herrsching, 2011.

168. O. Bulakci, A. Saleh, S. Redana, B. Raaf and J. Hamalainen, "Flexible Backhaul Resource Sharing and Uplink Power Control Optimization in LTE-Advanced Relay Networks," in IEEE Vehicular Technology Conference (VTC Fall), San Francisco, CA, 2011.

169. T. Liu and M. Rong, "Utility-based joint routing and spectrum partitioning in relay LTE-advanced networks," in IEEE 22nd International Symposium on Personal Indoor and Mobile Radio Communications (PIMRC), Toronto, ON , 2011.

170. 3GPP TR 36.814, "Evolved Universal Terrestrial Radio Access (EUTRA); Further advancements for E-UTRA physical layer aspects," 3rd Generation Partnership Project (3GPP).

171. A. Bou Saleh, O. Bulakci, Z. Ren, S. Redana, B. Raaf and J. Haemaelaeinen, "Resource Sharing in Relay-enhanced 4G Networks," in 11th European Wireless Conference - Sustainable Wireless Technologies (European Wireless), Vienna, Austria, 2011.

172. G. Liebl, T. de Moraes, A. Soysal and E. Seidel, "Fair resource allocation for inband relaying in LTE-Advanced," in 8th International Workshop on Multi-Carrier Systems \& Solutions (MC-SS), Herrsching, 2011.

173. G. Liebl, T. de Moraes, A. Soysal and E. Seidel, "Fair resource allocation for the relay backhaul link in LTEAdvanced," in IEEE Wireless Communications and Networking Conference (WCNC), Shanghai, 2012.

174. T. M. d. Moraes, G. Bauch and E. Seidel, "QoS-aware Scheduling for In-Band Relays in LTE-Advanced," in 9th International ITG Conference on Systems, Communication and Coding (SCC), Deutschland, 2013.

175. A. Yaver, D. Kolmas and J. Lachowski, "Resource utilization with relays in LTE-Advanced networks," in 24th Canadian Conference on Electrical and Computer Engineering (CCECE), Niagara Falls, ON, 2011. 
176. K. Sundaresan and S. Rangarajan, "Adaptive resource scheduling in wireless OFDMA relay networks," in IEEE INFOCOM, Orlando, FL, 2012.

177. L. Dong, X. Zhu and Y. Huang, "Optimal Asymmetric Resource Allocation for Multi-Relay Based LTE-Advanced Systems," in IEEE Global Telecommunications Conference, Houston, TX, 2011.

178. A. Nakajima, H. Masuda and H. Otsuka, "Practical design method for interferences between backhaul and access links in fiber-optic relay node," in IEEE International Conference on Signal Processing, Communication and Computing (ICSPCC), Hong Kong, 2012.

179. Z. Ma, W. Xiang, H. Long and W. Wang, "Proportional Fair Resource Partition for LTE-Advanced Networks with Type I Relay Nodes," in IEEE International Conference on Communications (ICC), Kyoto, 2011.

180. Z. Zhao, J. Wang, S. Redana and B. Raaf, "Downlink Resource Allocation for LTE-Advanced Networks with Type1 Relay Nodes," in IEEE Vehicular Technology Conference (VTC Fall), Quebec City, QC, 2012.

181. Y. Yuan, S. Wu, J. Yang, F. Bi, S. Xia and G. Li, "Relay backhaul subframe allocation in LTE-Advanced for TDD," in 5th International ICST Conference on Communications and Networking in China (CHINACOM), Beijing, 2010.

182. S. Yi and M. Lei, "Backhaul resource allocation in LTE-Advanced relaying systems," in IEEE Wireless Communications and Networking Conference (WCNC), Shanghai, 2012.

183. Y. Yuda, A. Iwata and D. Imamura, "Interference Mitigation Using Coordinated Backhaul Timing Allocation for LTEAdvanced Relay Systems," in IEEE International Conference on Communications (ICC), Kyoto, 2011.

184. K. Zheng, B. Fan, J. Liu, Y. Lin and W. Wang, "Interference coordination for OFDM-based multihop LTE-advanced networks," IEEE Wireless Communications, vol. 18, no. 1, pp. 54 - 63, 2011.

185. J. Gora and S. Redana, "In-band and out-band relaying configurations for dual-carrier LTE-advanced system," in IEEE 22nd International Symposium on Personal Indoor and Mobile Radio Communications (PIMRC), Toronto, ON, 2011.

186. J. Gora, "Interference mitigation for multi-carrier relay-enhanced networks," in 8th International Symposium on Wireless Communication Systems (ISWCS), Aachen, 2011.

187. H.-G. Ryu and H. Jeong, "Wireless repeater with equalization of feedback channel and phase noise for LTE-Advanced uplink," in 14th International Conference on Advanced Communication Technology (ICACT), PyeongChang, 2012.

188. H. Jeong and H.-G. Ryu, "Wireless repeater with adaptive equalizer and phase noise compensator for LTE-Advanced uplink," in IEEE MTT-S International Microwave Workshop Series on Intelligent Radio for Future Personal Terminals (IMWS-IRFPT), Daejeon, 2011.

189. A. Bou Saleh, S. Redana, B. Raaf, T. Riihonen, J. Hamalainen and R. Wichman, "Performance of Amplify-andForward and Decode-and-Forward Relays in LTE-Advanced," in Vehicular Technology Conference, Anchorage, AK, 2009.

190. S. Nagata, Y. Yan, X. Gao, A. Li, H. Kayama, T. Abe and T. Nakamura, "Investigation on System Performance of L1/L3 Relays in LTE-Advanced Downlink," in IEEE 73rd Vehicular Technology Conference (VTC Spring), Yokohama, 2011.

191. A. Lo and P. Guan, "Performance of in-band full-duplex Amplify-and-Forward and Decode-and-Forward relays with spatial diversity for next-generation wireless broadband," in International Conference on Information Networking (ICOIN), Barcelona, 2011.

192. F. Vitiello, T. Riihonen, J. Hamalainen and S. Redana, "On Buffering at the Relay Node in LTE-Advanced," in Vehicular Technology Conference, San Francisco, CA, 2011.

193. Q. Li, R. Hu, Y. Qian and G. Wu, "Cooperative communications for wireless networks: techniques and applications in LTE-advanced systems," IEEE Wireless Communications, vol. 19, no. 2, 2012.

194. C. Hoymann, W. Chen, J. Montojo, A. Golitschek, C. Koutsimanis and X. Shen, "Relaying operation in 3GPP LTE: challenges and solutions," IEEE Communications Magazine, vol. 50, no. 2, pp. 156 - 162, 2012.

195. J. Liu, R. Love and A. Nimbalker, "Recent Results on Relaying for LTE-Advanced," in IEEE 70th Vehicular Technology Conference Fall (VTC 2009-Fall), Anchorage, AK, 2009.

196. L. Rong, S. Elayoubi and O. Haddada, "Impact of Relays on LTE-Advanced Performance," in IEEE International Conference on Communications (ICC), Cape Town, 2010.

197. A. Lo and I. Niemegeers, "Multi-hop relay architectures for 3GPP LTE-advanced," in IEEE 9th Malaysia International Conference on Communications (MICC), Kuala Lumpur, 2009.

198. K. Zheng, B. Fan, Z. Ma, G. Liu, X. Shen and W. Wang, "Multihop cellular networks toward LTE-advanced," IEEE Vehicular Technology Magazine, vol. 4, no. 3, pp. 40 - 47, 2009.

199. Y. Yang, H. Hu, J. Xu and G. Mao, "Relay technologies for WiMax and LTE-advanced mobile systems," IEEE Communications Magazine, vol. 47, no. 10, pp. 100 - 105, 2009.

200. K. Loa, C.-C. Wu, S.-T. Sheu, Y. Yuan, M. Chion, D. Huo and L. Xu, "IMT-advanced relay standards [WiMAX/LTE Update]," IEEE Communications Magazine, vol. 48, no. 8, pp. 40 - 48, 2010.

201. F.-H. Tseng, C.-Y. Chen, L.-D. Chou, T.-Y. Wu and H.-C. Chao, "A Study on Coverage Problem of Network Planning in LTE-Advanced Relay Networks," in International Conference on Advanced Information Networking and Applications (AINA), Fukuoka, 2012.

202. A. Saleh, O. Bulakci, J. Hämäläinen, S. Redana and B. Raaf, "Analysis of the Impact of Site Planning on the Performance of Relay Deployments," IEEE Transactions on Vehicular Technology, vol. 61, no. 7, pp. 3139 - 3150 , 2012.

203. O. Bulakci, S. Redana, B. Raaf and J. Hamalainen, "Performance Enhancement in LTE-Advanced Relay Networks via Relay Site Planning," in IEEE 71st Vehicular Technology Conference, Taipei, 2010.

204. S. Khakurel, M. Mehta and A. Karandikar, "Optimal relay placement for coverage extension in LTE-A cellular systems," in National Conference on Communications (NCC), Kharagpur, 2012. 
205. O. Elgendy, M. Ismail and K. Elsayed, "On the relay placement problem in a multi-cell LTE-Advanced system with cochannel interference," in IEEE 8th International Conference on Wireless and Mobile Computing, Networking and Communications (WiMob), Barcelona, 2012.

206. Q. H. Chu, J.-M. Conrat and J. Cousin, "On the impact of receive antenna height in a LTE-Advanced relaying scenario," in European Wireless Technology Conference (EuWIT), Paris, 2010.

207. Q. H. Chu, J.-M. Conrat and J. Cousin, "Propagation path loss models for LTE-advanced urban relaying systems," in IEEE International Symposium on Antennas and Propagation (APSURSI), Spokane, WA, 2011.

208. T. Beniero, S. Redana, J. Hamalainen and B. Raaf, "Effect of Relaying on Coverage in 3GPP LTE-Advanced," in IEEE 69th Vehicular Technology Conference, Barcelona, 2009.

209. T. Wirth, V. Venkatkumar, T. Haustein, E. Schulz and R. Halfmann, "LTE-Advanced Relaying for Outdoor Range Extension," in IEEE 70th Vehicular Technology Conference Fall (VTC 2009-Fall), Anchorage, AK, 2009.

210. Y. Wang, G. Feng and Y. Zhang, "Cost-Efficient Deployment of Relays for LTE-Advanced Cellular Networks," in IEEE International Conference on Communications (ICC), Kyoto, 2011.

211. E. Lang, S. Redana and B. Raaf, "Business Impact of Relay Deployment for Coverage Extension in 3GPP LTEAdvanced," in IEEE International Conference on Communications Workshops, Dresden, 2009.

212. M. Minelli, M. Coupechoux, J. Kelif, M. Ma and P. Godlewski, "Relays-Enhanced LTE-Advanced Networks Performance Studies," in Sarnoff Symposium, Princeton, NJ, 2011.

213. V. Venkatkumar, T. Wirth, T. Haustein and E. Schulz, "Relaying in Long Term Evolution: Indoor full frequency reuse," in European Wireless Conference, Aalborg, 2009.

214. R. Irmer and F. Diehm, "On coverage and capacity of relaying in LTE-advanced in example deployments," in IEEE 19th International Symposium on Personal, Indoor and Mobile Radio Communications, Cannes, 2008.

215. C. Coletti, P. Mogensen and R. Irmer, "Performance Analysis of Relays in LTE for a Realistic Suburban Deployment Scenario," in IEEE 73rd Vehicular Technology Conference (VTC Spring), Budapest, 2011.

216. O. Yilmaz, E. Mutafungwa and J. Hamalainen, "Performance of relay enhanced LTE-Advanced networks for selected suburban scenarios in emerging market environments," in International Symposium on Wireless Communication Systems (ISWCS), Paris, 2012.

217. C. Coletti, P. Mogensen and R. Irmer, "Deployment of LTE In-Band Relay and Micro Base Stations in a Realistic Metropolitan Scenario," in Vehicular Technology Conference, San Francisco, CA, 2011.

218. R. Fantini, D. Sabella and M. Caretti, "Energy Efficiency in LTE-Advanced Networks with Relay Nodes," in IEEE 73rd Vehicular Technology Conference (VTC Spring), Yokohama, 2011.

219. Y. Li, M. Peng, J. Jiang and L. Dong, "An adaptive energy saving mechanism in LTE-advanced relay systems," in 7th International ICST Conference on Communications and Networking in China (CHINACOM), Kun Ming, 2012.

220. L. Mroueh and E. Vivier, "Energy efficient relaying PHY-MAC strategy for LTE-advanced networks," in International Symposium on Wireless Communication Systems (ISWCS), Paris, 2012.

221. R. Fantini, D. Sabella and M. Caretti, "An E3F based assessment of energy efficiency of relay nodes in LTE-advanced networks," in IEEE 22nd International Symposium on Personal Indoor and Mobile Radio Communications (PIMRC), Toronto, ON, 2011.

222. G. Chandwani, S. Datta and S. Chakrabarti, "Relay assisted cellular system for energy minimization," in India Conference (INDICON), Kolkata, 2010.

223. A. Saleh, O. Bulakci, S. Redana, B. Raaf and J. Hamalainen, "A divide-and-conquer approach to mitigate relay-to-relay interference," in IEEE 22nd International Symposium on Personal Indoor and Mobile Radio Communications (PIMRC), Toronto, ON, 2011.

224. A. Karaer, O. Bulakci, S. Redana, B. Raaf and J. Hamalainen, "Uplink Performance Optimization in Relay Enhanced LTE-Advanced Networks," in International Symposium on Personal, Indoor and Mobile Radio Communications, Tokyo, 2009.

225. N. Krishnan, J. Panchal, N. Mandayam and R. Yates, "Bandwidth Sharing in LTE-A Relaying Systems," in Annual Allerton Conference on Communication, Control, and Computing, Allerton, IL, 2010.

226. N. Krishnan, R. Yates, N. B. Mandayam and J. Panchal, "Bandwidth Sharing for Relaying in Cellular Systems," IEEE Transactions on Wireless Communications, vol. 11, no. 1, pp. 117 - 129, 2012.

227. A. Alizadeh, S. M.-S. Sadough and S. A. Ghorashi, "Relay Selection and Resource Allocation in LTE-Advanced Cognitive Relay Networks," International Journal on Communications Antenna and Propagation (I.Re.C.A.P.), vol. 1, no. 4 , pp. $303-310,2011$.

228. R. Combes, Z. Altman and E. Altman, "Self-Organizing Relays: Dimensioning, Self-Optimization, and Learning," IEEE Transactions on Network and Service Management, vol. 9, no. 4, pp. 487 - 500, 2012.

229. K. Samdanis and M. Brunner, "Self-organized network management functions for relay enhanced LTE-advanced systems," in IEEE 22nd International Symposium on Personal Indoor and Mobile Radio Communications (PIMRC), Toronto, ON, 2011.

230. V. V. Phan, K. Horneman, L. Yu and J. Vihriala, "Providing enhanced cellular coverage in public transportation with smart relay systems," in IEEE Vehicular Networking Conference (VNC), Jersey City, NJ, 2010.

231. W. Zirwas, U. Zeeshan and M. Grieger, "Cooperative feeder links for relay enhanced networks," in 18th European Wireless Conference, Poznan, Poland, 2012.

232. R. Gohary and H. Yanikomeroglu, "An emerging concept for $4 \mathrm{G}+$ wireless cellular networks: Terminal relaying," in Saudi International Electronics, Communications and Photonics Conference (SIECPC), Riyadh, 2011.

233. S. Andreev, O. Galinina and A. Turlikov, "Basic client relay model for wireless cellular networks," in International Congress on Ultra Modern Telecommunications and Control Systems and Workshops (ICUMT), Moscow, 2010.

234. Q. Chen, Y. Li and L. Tang, "An Effective Relay Coordination Scheme Based on Opportunistic Relaying for LTEAdvanced," in International Conference on Wireless Networks and Information Systems, Shanghai, 2009. 
235. R. Shrivastava and M. Aguayo-Torres, "Analysis and evaluation of Cooperative Multi-Point transmission/reception and soft handover for LTE-Advanced," in World Congress on Information and Communication Technologies (WICT), Trivandrum, 2012.

236. M. Sawahashi, Y. Kishiyama, A. Morimoto, D. Nishikawa and M. Tanno, "Coordinated multipoint transmission/reception techniques for LTE-advanced [Coordinated and Distributed MIMO]," IEEE Wireless Communications, vol. 17, no. 3, pp. 26 - 34, 2010.

237. J. Lee, Y. Kim, H. Lee, B. L. Ng, D. Mazzarese, J. Liu, W. Xiao and Y. Zhou, "Coordinated multipoint transmission and reception in LTE-advanced systems," IEEE Communications Magazine, vol. 50, no. 11, pp. 44 - 50, 2012.

238. Z. Feng, W. Muqing and L. Huixin, "Coordinated Multi-Point Transmission and Reception for LTE-Advanced," in 5th International Conference on Wireless Communications, Networking and Mobile Computing, Beijing, 2009.

239. S. Sun, Q. Gao, Y. Peng, Y. Wang and L. Song, "Interference management through CoMP in 3GPP LTE-advanced networks," IEEE Wireless Communications, vol. 20, no. 1, pp. 59 - 66, 2013.

240. G. Youjun, W. Qixing and L. GuangYi, "The Access Network and Protocol Design for CoMP Technique in LTEAdvanced System," in 6th International Conference on Wireless Communications Networking and Mobile Computing (WiCOM), Chengdu, 2010.

241. J. Jin, Q. Wang, L. Zeng, H. Yang and Y. Wang, "Coordinated multiple point reception scheme for the uplink of LTEadvanced system," in 15th Asia-Pacific Conference on Communications, Shanghai, 2009.

242. Q. Wang, D. Jiang, G. Liu and Z. Yan, "Coordinated Multiple Points Transmission for LTE-Advanced Systems," in 5th International Conference on Wireless Communications, Networking and Mobile Computing, Beijing, 2009.

243. J. Giese, M. Amin and S. Brueck, "Application of coordinated beam selection in heterogeneous LTE-advanced networks," in 8th International Symposium on Communication Systems (ISWCS), Aachen, 2011.

244. X. Lin, S. Jin, X. Li and X. Gao, "System-level performance of coordinated multi-point transmission for heterogeneous networks in LTE-Advanced systems," in International Conference on Wireless Communications \& Signal Processing (WCSP), Huangshan, 2012.

245. Y. Gao, Y. Li, H. Yu and S. Gao, "Performance analysis of dynamic CoMP cell selection in LTE-advanced Heterogeneous Networks scenario," in International Conference on Uncertainty Reasoning and Knowledge Engineering (URKE), Bali, 2011.

246. Y.-N. R. Li, J. Li, W. Li, Y. Xue and H. Wu, "CoMP and interference coordination in heterogeneous network for LTEAdvanced," in IEEE Globecom Workshops (GC Wkshps), Anaheim, CA, 2012.

247. C.-P. Chien, K.-M. Yang and H.-Y. Hsieh, "Selection of transmission points for delay minimization in LTE-A heterogeneous networks with low-power RRHs," in IEEE Wireless Communications and Networking Conference (WCNC), Shanghai, 2013.

248. Y. Li, J. Li, L. Zhang and M. Peng, "Adaptive heterogeneous coordinated beamforming algorithm in LTE-advanced systems," in IEEE Wireless Communications and Networking Conference (WCNC), Shanghai, 2013.

249. M. Simsek, M. Bennis and A. Czylwik, "Coordinated beam selection in LTE-Advanced HetNets: A reinforcement learning approach," in IEEE Globecom Workshops (GC Wkshps), Anaheim, CA, 2012.

250. D. Lee, H. Seo, B. Clerckx, E. Hardouin, D. Mazzarese, S. Nagata and K. Sayana, "Coordinated multipoint transmission and reception in LTE-advanced: deployment scenarios and operational challenges," IEEE Communications Magazine, vol. 50, no. 2, pp. 148 - 155, 2012.

251. Y.-H. Nam, L. Liu, Y. Wang, C. Zhang, J. Cho and J.-k. Han, "Cooperative communication technologies for LTEadvanced," in IEEE International Conference on Acoustics Speech and Signal Processing (ICASSP), Dallas, TX, 2010.

252. H. Je, H. Lee, K. Kwak, S. Choi, Y.-J. Hong and B. Clerckx, "Long-Term Channel Information-Based CoMP Beamforming in LTE-Advanced Systems," in IEEE Global Telecommunications Conference, Houston, TX, USA, 2011.

253. C. Khirallah, D. Vukobratovic and J. Thompson, "On Energy Efficiency of Joint Transmission Coordinated Multi-Point in LTE-Advanced," in International ITG Workshop on Smart Antennas (WSA), Dresden, 2012.

254. K. Huq, S. Mumtaz, M. Alam, A. Radwan and J. Rodriguez, "Energy efficient CoMP transmission in LTE-Advanced," in IEEE Globecom Workshops (GC Wkshps), Anaheim, CA, 2012.

255. Y. Li, J. Ge, C. Shen, J. Li and W. Miao, "Coordinated multi-point transmission with limited feedback for LTEadvanced," in 11th International Symposium on Communications and Information Technologies (ISCIT), Hangzhou, 2011.

256. ITU-R M.2078, "Estimated spectrum bandwidth requirements for the future development of IMT-2000 and IMTAdvanced," 2006. 